\title{
Analysis and Design of UHF Bow-Tie RFID Tag Antenna Input Impedance
}

\author{
D. A. Abd El-Aziz'1, T. G. Abouelnaga'2, E. A. Abdallah'2, M. El-Said³, Yaser S. E. Abdo' ${ }^{1}$ \\ ${ }^{1}$ National Institute for Standards, Giza, Egypt \\ ${ }^{2}$ Electronics Research Institute, Giza, Egypt \\ ${ }^{3}$ Faculty of Engineering, Cairo University, Giza, Egypt \\ Email: eng.dina_ali@hotmail.com, taer@eri.sci.eg, moelsaid@hotmail.com, esmataa2@hotmail.com, \\ vaserabdo76@gmail.com
}

Received 15 May 2016; accepted 19 June 2016; published 22 June 2016

Copyright (C) 2016 by authors and Scientific Research Publishing Inc.

This work is licensed under the Creative Commons Attribution International License (CC BY).

http://creativecommons.org/licenses/by/4.0/

c) (i) Open Access

\begin{abstract}
In this paper two proposed methods of input impedance calculation for Bow-Tie antenna are introduced. The proposed methods show input impedance calculation with high accuracy. Also, design curves for input impedance values were developed depending on the geometry of antenna. The proposed design curves are used to design a Bow-Tie type RFID tag antenna. The input impedance of the tag antenna is calculated using proposed methods and compared with that obtained using CST studio suite 2014 and IE3D Zeland version 12.0 software packages. The results are investigated and discussed. The tag antenna is fabricated, measured and the obtained input impedance is compared with the simulation and the proposed methods. Good agreement among measured input impedance and that simulated by CST, IE3D or proposed methods is obtained.
\end{abstract}

\section{Keywords}

Bandwidth, Bow-Tie Antenna, Radio Frequency Identification (RFID), Ultra High Frequency (UHF)

\section{Introduction}

RFID system consists of reader and tag. The reader interrogates the tags via a wireless link to obtain the data stored on the tags. The tag consists of an antenna and a chip which has an input impedance of complex value. In order to achieve a good performance and low power consumption, chip impedance should be correctly matched to tag antenna. The cheapest RFID tags with the largest commercial potential are passive or semi-passive, where the energy necessary for tag-reader communication is harvested from the reader's signal or the surrounding environment. The most important requirements for tag antenna are extremely low power consumption, small size, 
and low cost. Dipole configurations including the Cylindrical [1], Biconical [2] and Bow-Tie [3] have been used as a wide-band antenna for their simple structures and low cost. The Bow-Tie structure was first proposed by George et al. [4]. A hybrid approach involving Bacterial Swarm Optimization (BSO) and Nelder-Mead (NM) algorithm was used to design a Bow-Tie antenna for $2.45 \mathrm{GHz}$ Radio Frequency Identification (RFID) readers. The Bow-Tie antenna was made from a bi-triangular metal sheet with the feed at its vertex. The antenna dimensions: half-height, feeding neck width, and flare angle were optimized to be $21.078 \mathrm{~mm}, 3.4818 \mathrm{~mm}, 48.555^{\circ}$, respectively and matched to input impedance of $50 \Omega$ [5]. This antenna gives an excellent reflection coefficient $\left|S_{11}\right|$ result equal to $-111.96 \mathrm{~dB}$ at $2.45 \mathrm{GHz}$. A T-matched quadrate Bow-Tie antenna (half wavelength dipole antenna) with rounded corners was designed and fabricated with dimensional length $92 \mathrm{~mm}$ and width $31.8 \mathrm{~mm}$ [6]. This design was used for the matching of the passive antenna terminals to (UCODE G2XM) IC chip impedance $(22-j 191 \Omega)$ at resonance frequency of $915 \mathrm{MHz}$. An ultra-wideband cavity-backed Bow-Tie antenna with the parasitic dipole and parasitic circular ring was designed and fabricated with three layers including the upper substrate layer, the lower substrate layer and the ground plane. Both substrates with permittivity of 2.65, a thickness of $1 \mathrm{~mm}$ are supported by the plastic posts, loss tangent of 0.003, a radius of $62 \mathrm{~mm}$ [7]. An ultra-wideband impedance characteristic of about $118.2 \%$ for VSWR $\leq 2$ ranging from 2.75 to $10.7 \mathrm{GHz}$ was achieved. A unidirectional radiation pattern, a stable peak gain of around $7.4-10.8 \mathrm{dBi}$ and low cross polarization over the whole operating band were also produced. A wideband directional Bow-Tie antenna with stable radiation patterns fed by a wideband microstrip balun using a coupling triangular structure to induce more balanced current was built on a substrate with thickness of $1 \mathrm{~mm}$ and relative permittivity $\varepsilon_{r}=2.65$ and it's dimensions were $70 \times 40 \mathrm{~mm}^{2}$ [8]. The antenna was designed to cover the band from $1.97 \mathrm{GHz}$ to $6.49 \mathrm{GHz}$ and achieved a stable gain of around $9.5 \mathrm{dBi}$ with unidirectional and symmetrical radiation patterns in both E- and $\mathrm{H}$-planes across the whole operating band. A Bow-Tie microstrip antenna was designed to overcome the high path loss and achieve bandwidth requirement in sea water from $2.4 \mathrm{GHz}$ to $5.1 \mathrm{GHz}$. The antenna was used in WLAN communications and its dimensions was $1.4 \mathrm{~cm}^{2}$ [9]. The aforementioned literatures indicate that, in the recent few years, a great effort was made and good results were obtained where the antenna was matched to a 50 Ohm input impedance but the main problem will arise when a complex matching is needed. This problem arises clearly in the design requirements of UHF tag antenna. In this paper, a Bow-Tie tag antenna which is matched to a complex chip input impedance and also to achieve a wide bandwidth is proposed. Also, two proposed methods of input impedance calculation of Bow-Tie antenna are introduced.

The paper is organized as follows: Section 2 gives the Bow-Tie antenna input impedance calculation as in the published literatures, namely quasi-static method, tapered transmission line method and biconical approximation method. It also includes the proposed analytical and graphical methods. The conventional Bow-Tie tag antenna is given in Section 3, while the modified tag antenna design results are given in Section 4. Section 5 gives the experimental results, while Section 6 introduces the conclusions.

\section{Bow-Tie Antenna Input Impedance Calculation}

The design of Bow-Tie antenna [10] is simple since the antenna structure is completely defined by its angle $\theta$ and length $L_{1}$, Figure 1 . The Bow-Tie antenna angle determines the antenna impedance and the length determines the operation bandwidth.

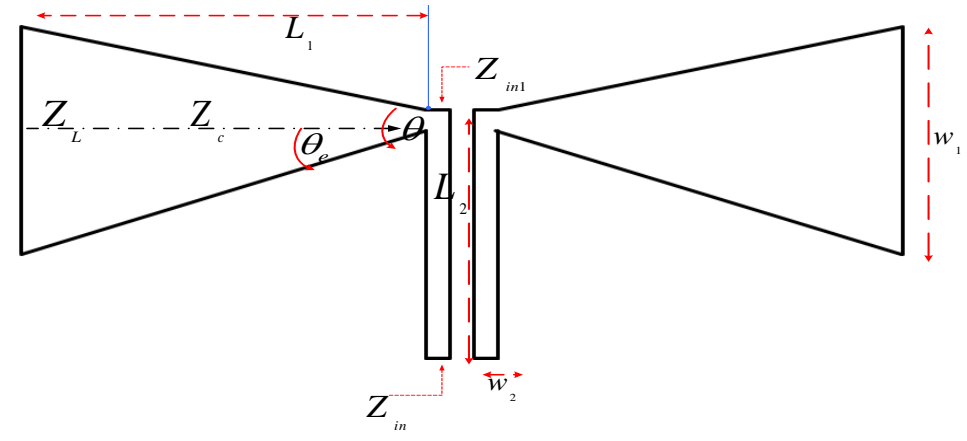

Figure 1. Conventional Bow-Tie antenna geometry. 


\subsection{Quasi-Static Method}

This method was used to calculate the characteristic impedance of Bow-Tie antenna [11]. The theoretical quasi-static impedance $Z_{q s}$ [3] of an infinite Bow-Tie printed on a dielectric half-space, obtained using conformal mapping is given by:

$$
Z_{q s}=\eta_{o} \sqrt{\frac{2}{\varepsilon_{r}+1}} \frac{K(k)}{K^{\prime}(k)}
$$

where $\eta_{o}$ is the free space wave impedance $(=120 \pi \Omega), \varepsilon_{r}$ is the substrate dielectric constant and $K(k)$ represents a complete elliptic integral function with argument $k$,

$$
k=\tan ^{2}\left(45^{\circ}-\theta / 4\right)
$$

and $K^{\prime}(k)$ : complementary function given by $K^{\prime}(k)=K\left(k^{\prime}\right)$

$$
k^{\prime}=\sqrt{1-k^{2}}
$$

Based on Equation (1) a matlab code is built and the results are shown in Figure 2. Referring to Figure 2, it can be noticed that a good agreement is found with the curves the curve of $Z_{q s}$ that was published in [10], in which it has been calculated as a function of bow-tie angle $\theta$ for different values of $\varepsilon_{r}$.

\subsection{Tapered Transmission Line Method}

In a multi-section quarter-wave transformer used to match two transmission lines with different characteristic impedances, the change in impedance level is obtained in a number of discrete steps. An alternative is to use a tapered transition which has characteristic impedance that varies continuously in a smooth fashion from the impedance of one line to that of the other line. A transition or matching section, of this type is referred to as a tapered transmission line [12], Figure 3.

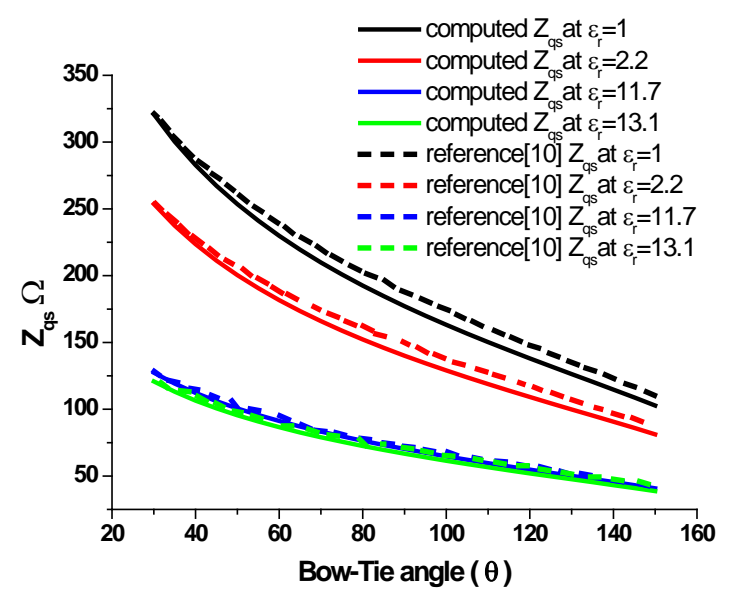

Figure 2. Quasi-static characteristic impedance $Z_{q s}$ versus bow-tie angle $\theta$ at different values of $\varepsilon_{r}$.

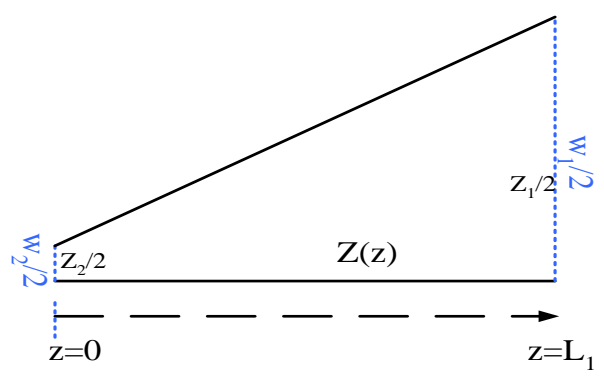

Figure 3. Tapered transmission line matching section. 
Wide line $\frac{w_{1} / 2}{h} \geq 1$ :

$$
\begin{aligned}
& \varepsilon_{\text {eff } 1}=\frac{\varepsilon_{r}+1}{2}+\frac{\varepsilon_{r}-1}{2}\left[\left(1+12 \frac{h}{w_{1} / 2}\right)^{-0.5}\right] \\
& Z_{1}=\frac{120 \pi}{\sqrt{\varepsilon_{\text {eff } 1}}\left(\frac{w_{1} / 2}{h}+1.393+0.667 \ln \left(\frac{w_{1} / 2}{h}+1.444\right)\right)} \times 2
\end{aligned}
$$

Narrow line $\left(\frac{w_{2} / 2}{h}\right) \leq 1$ :

$$
\begin{aligned}
& \varepsilon_{\text {eff } 2}=\frac{\varepsilon_{r}+1}{2}+\frac{\varepsilon_{r}-1}{2}\left[\left(1+12 \frac{h}{w_{2} / 2}\right)^{-0.5}+0.04\left(1-\frac{w_{2} / 2}{h}\right)^{2}\right] \\
& Z_{2}=\frac{60}{\sqrt{\varepsilon_{\text {eff } 2}}} \ln \left(\frac{8 h}{w_{2} / 2}+0.25 \frac{W_{2} / 2}{h}\right) \times 2 \\
& Z(z)=Z_{2}\left[1+\left(\frac{Z_{1}}{Z_{2}}-1\right) \frac{Z}{L_{1}}\right]
\end{aligned}
$$

Taking the average value of $Z(z)$ :

$$
Z_{a v .}=Z(z) / \text { number of stepsin length }
$$

where $w_{1} / 2$ is the half width at impedance $Z_{1} / 2, w_{2} / 2$ is the half width at impedance $Z_{2} / 2$ [1] [13], Figure $3, \varepsilon_{\text {eff } 1}, \varepsilon_{\text {eff } 2}$ are the effective dielectric constants at $w_{1} / 2$ and $w_{2} / 2, h$ is the height of dielectric substrate, $Z(z)$ is the characteristic impedance function of distance $z$ along the taper and $L_{1}$ is the length of the taper.

\subsection{Biconical Approximation Method}

The problem of finding the input terminal resistance and also reactance taking into account the effect of conductor thickness is most simply approach by Schelkunoff's treatment of the biconical antenna. This method was used to determine the characteristic impedance of finite biconical antenna [2]. This is analogues to finite or terminated transmission line. A TEM mode wave can exist along the biconical conductor, but in the space beyond the cones transmission can be only in higher order modes. Schelkunoff's has defined the sphere coinciding with the ends of the cones as a boundary sphere and the sphere radius is equal to radius of cone $\left(r=L_{1}\right)$. Inside the sphere TEM wave can exist and also higher order modes may be presented, but outside only the higher order modes can exist. At the cones most of the outgoing TEM wave is reflected, but near the equator most of the energy escapes, Figure 4(a). But a step of imagine from the impedance view point, the magnetic shell acting as a load impedance $Z_{L}$ connected across the open end of the cones. Neglecting the end caps of the cones, the finite biconical antenna can now be treated as a transmission line of characteristic impedance $Z_{k}$ terminated in the load impedance $Z_{L}$, Figure 4(b). If the load impedance $Z_{L}$ can be found, the impedance $Z_{i n 1}$ at the input terminal of biconical antenna can be calculable.

$$
Z_{k}=120 \ln \cot \left(\theta_{e} / 2\right)
$$

where $Z_{k}$ is the characteristic impedance of finite biconical antenna and $\theta_{e}$ is the half angle of the cone.

$$
\begin{aligned}
& Z_{\text {in } 1}=Z_{k} \frac{Z_{L}+j Z_{k} \tan \left(\beta_{1} L_{1}\right)}{Z_{k}+j Z_{L} \tan \left(\beta_{1} L_{1}\right)} \\
& \beta_{1}=\frac{2 \pi}{\lambda}=\frac{2 \pi}{\lambda_{o}} \sqrt{\varepsilon_{\text {eff } 1}}
\end{aligned}
$$




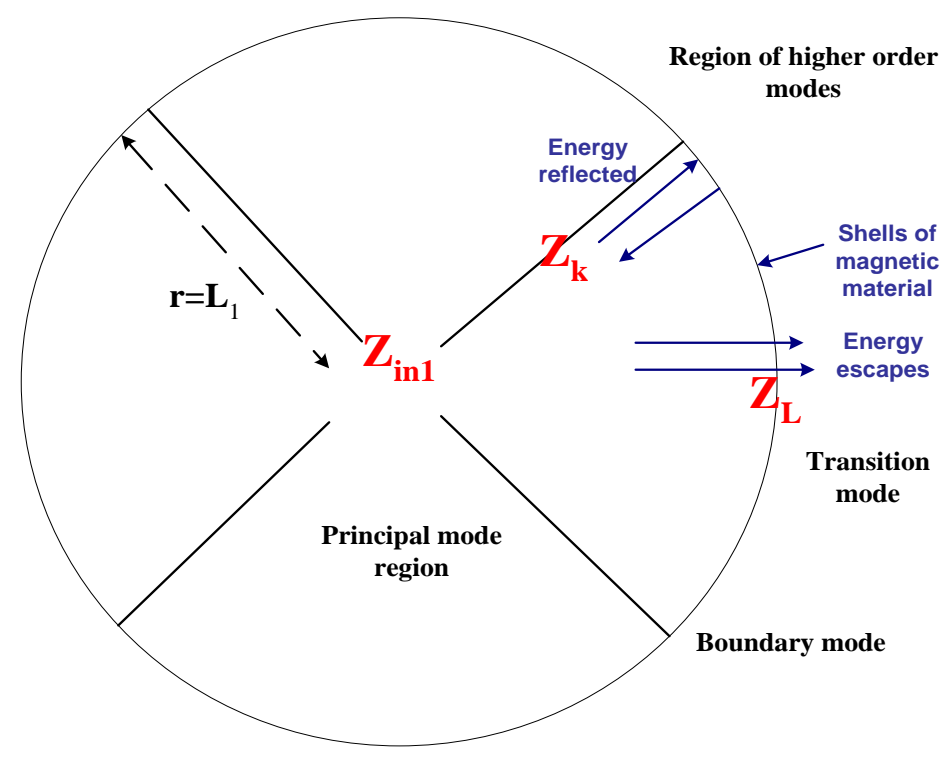

(a)

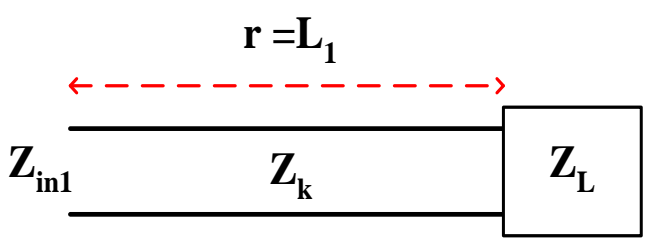

(b)

Figure 4. (a) Schelkunoff's finite biconical antenna and boundary sphere; (b) Equivalent transmission line.

where $\beta_{1}$ is the phase constant for bow-tie width $w_{1}$, Figure $1, \lambda_{o}$ is the free space wavelength, $\lambda$ is the guide wave length, and $\varepsilon_{\text {eff } 1}$ was derived by substituting $w_{1}$ instead of $w_{1} / 2$ in Equation (4).

Schelkunoff's method was used to determine $Z_{L}$. This method consists first of calculating $Z_{m}$ at current maximum on a very thin biconical antenna, a sinusoidal current distribution being assumed, where $Z_{m}$ is the impedance which appears between the current maximum on one cone and corresponding point on other cone. Since this impedance occurs at $\lambda / 4$ from the open end of the antenna, $Z_{L}$ is then equal to $Z_{m}$ transformed a line $\lambda / 4$, Figure 5(a). Finally, the input impedance $Z_{i n 1}$ is $Z_{L}$ transformed over a line of characteristic impedance $Z_{k}$ and length $L_{1}$, Figure 5(b).

$$
Z_{L}=Z_{k} \frac{Z_{m}+j Z_{k} \tan (\beta x)}{Z_{k}+j Z_{m} \tan (\beta x)}
$$

and since $\beta x=\pi / 2$, so

$$
Z_{L}=Z_{k}^{2} / Z_{m}
$$

where $\beta=\frac{2 \pi}{\lambda}$ is the phase constant, and $x$ is equal to $\lambda / 4$.

$$
\begin{aligned}
Z_{m}= & R_{m}+j X_{m} \\
R_{m}= & 60 \operatorname{Cin}\left(2 \beta_{1} L_{1}\right)+30\left(0.577+\ln \left(\beta_{1} L_{1}\right)-2 \operatorname{Ci}\left(2 \beta_{1} L_{1}\right)+\operatorname{Ci}\left(4 \beta_{1} L_{1}\right)\right) \cos \left(2 \beta_{1} L_{1}\right) \\
& +30\left(\operatorname{Si}\left(4 \beta_{1} L_{1}\right)-2 \operatorname{Si}\left(2 \beta_{1} L_{1}\right)\right) \sin \left(2 \beta_{1} L_{1}\right) \\
X_{m}= & 60 \operatorname{Si}\left(2 \beta_{1} L_{1}\right)+30\left(\operatorname{Ci}\left(4 \beta_{1} L_{1}\right)-\ln \left(\beta_{1} L_{1}\right)-0.577\right) \sin \left(2 \beta_{1} L_{1}\right)-30 \operatorname{Si}\left(4 \beta_{1} L_{1}\right) \cos \left(2 \beta_{1} L_{1}\right)
\end{aligned}
$$

$R_{m}$ is the radiation resistance at a current maximum of a very thin linear antenna, $X_{m}$ is the radiation reactance, $L_{1}$ is the length of one cone [2], Figure 5. Schelkunoff's has extended his analysis for thin biconical antennas as outlined above, to thin antennas of other shapes by considering the characteristic impedance of the antenna. So, on the same manner based on biconical approximation method, substitute in Equation (11) and Equation (13) to get the input impedance of Bow-Tie antenna $Z_{i n 1}$ and load impedance $Z_{L}$ using characteristic impedance based on quasi static method $Z_{q s}$ Equation (1), tapered transmission line method $Z_{a v}$. Equation (9).

The input impedance of Bow-Tie antenna and load impedance, Figure 1 are given by: 


$$
\begin{gathered}
Z_{i n 1}=Z_{c} \frac{Z_{c}+j Z_{L} \tan \left(\beta_{1} L_{1}\right)}{Z_{L}+j Z_{c} \tan \left(\beta_{1} L_{1}\right)} \\
Z_{L}=Z_{c} \frac{Z_{m}+j Z_{c} \tan (\beta x)}{Z_{c}+j Z_{m} \tan (\beta x)}
\end{gathered}
$$

where $Z_{c}$ is the characteristic impedance for different methods quasi static, Equation (1), tapered transmission line, Equation (9) and biconical methods, Equation (10).

A Bow-Tie antenna, Figure 6 was designed [14]. This antenna is fed with a characteristic impedance of value $Z_{o}=300 \Omega$ at $f=900 \mathrm{MHz}$. The corresponding parameters of this antenna are shown in Table 1.

The general input impedance $Z_{\text {in }}$, Figure 1 is given by

$$
\begin{aligned}
& Z_{\text {in }}=Z_{o} \frac{Z_{\text {in } 1}+j Z_{o} \tan \left(\beta_{2} L_{2}\right)}{Z_{o}+j Z_{\text {in } 1} \tan \left(\beta_{2} L_{2}\right)} \\
& \beta_{2}=\frac{2 \pi}{\lambda_{o}} \sqrt{\frac{\varepsilon_{\text {eff } 2}+1}{2}}
\end{aligned}
$$

where $\beta_{2}$ is the phase constant for feeding line width $w_{2}$, Figure $1, \varepsilon_{\text {eff } 2}$ was derived by substituting $w_{2}$ instead of $w_{2} / 2$ in Equation (6).

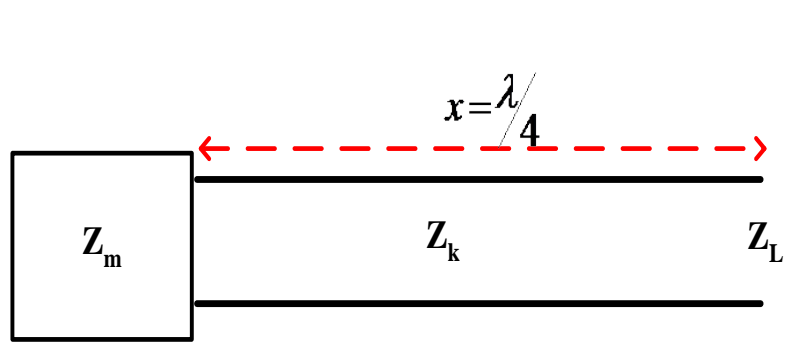

(a)
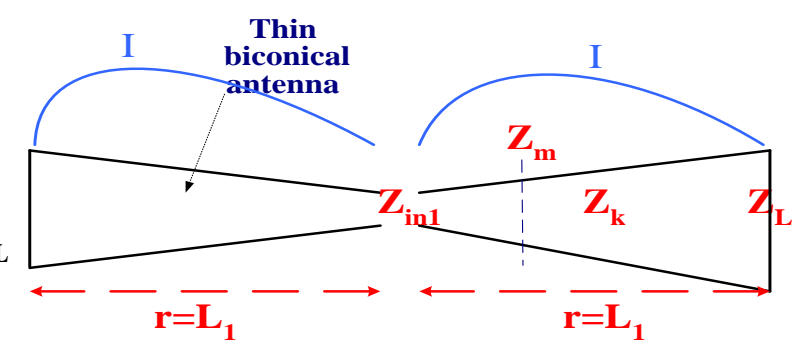

(b)

Figure 5. Thin finite biconcial antenna and transmission line equivalent for finding $Z_{L}$.

\begin{tabular}{|c|c|c|c|c|}
\hline Substrate material & $\varepsilon_{r}$ & $\tan (\delta)$ & Substrate thickness & $L$ \\
\hline FR4 & 4.3 & 0.02 & $1.6 \mathrm{~mm}$ & $114.34 \mathrm{~mm}$ \\
\hline$L_{1}$ & $W_{1}$ & $L_{2}$ & $W_{2}$ & $W$ \\
\hline $54.93 \mathrm{~mm}$ & $56 \mathrm{~mm}$ & $39.3 \mathrm{~mm}$ & $1.6 \mathrm{~mm}$ & $68.65 \mathrm{~mm}$ \\
\hline
\end{tabular}

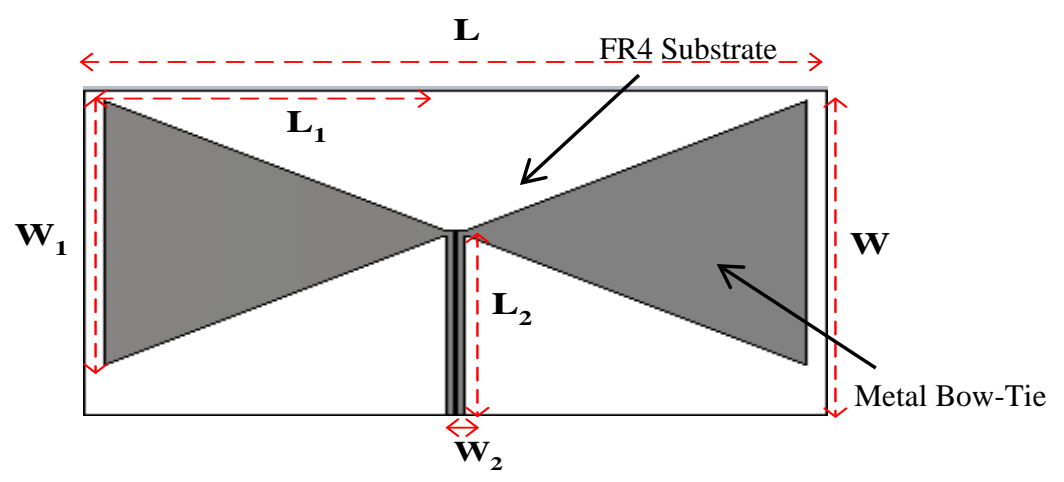

Figure 6. Traditional Bow-Tie antenna.

Table1. Traditional Bow-Tie antenna parameters at $900 \mathrm{MHz}$. 
The aforementioned methods were used to calculate the Bow-Tie antenna input impedance, Figure 7 and Figure 8. These figures indicate that the aforementioned conventional analytical methods for obtaining the Bow-Tie input impedance gave accurate results as indicated in Table 2. Also, proposed methodsare used to form alternative equation for solving the input impedance of Bow-Tie antenna presented in Section 2.4.

\subsection{Proposed Methods for Bow-Tie Antenna Input Impedance Calculation}

There are two proposed methods to obtain input impedance of Bow-Tie antenna, analytical and graphical.

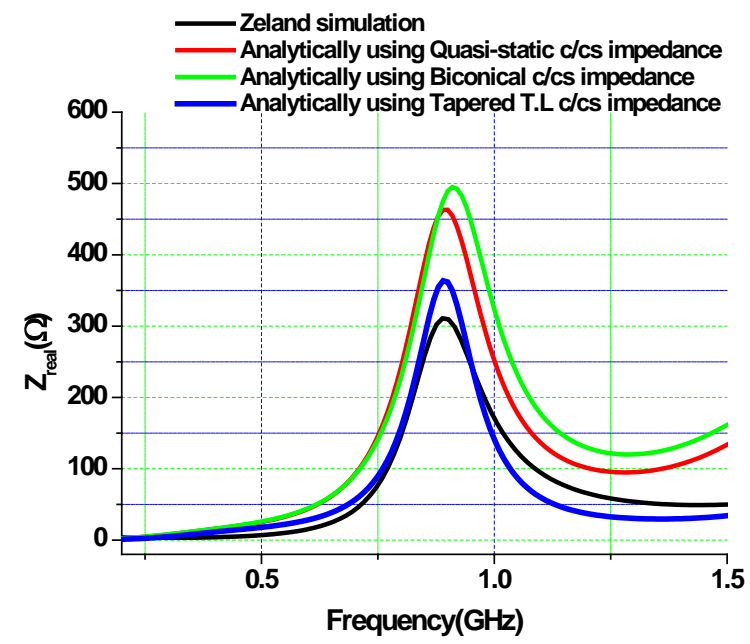

Figure 7. Bow-Tie antenna input impedance, real part.

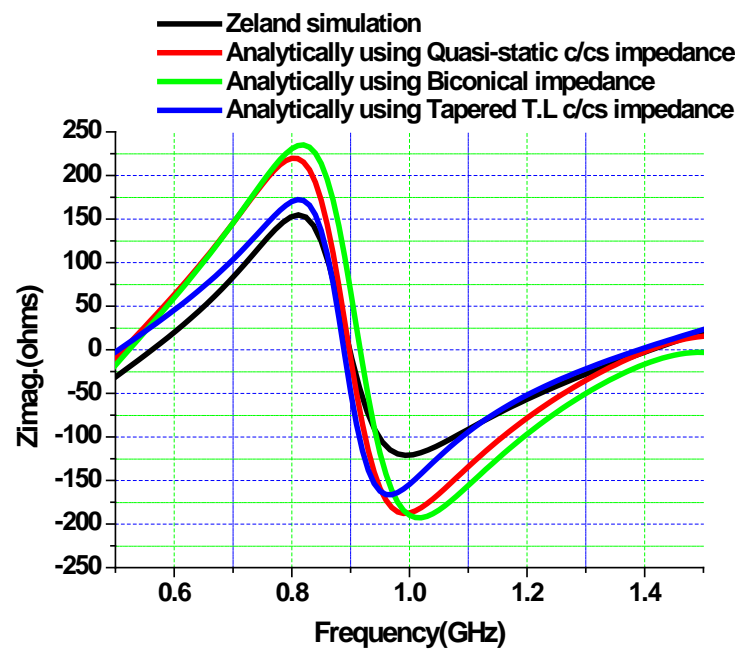

Figure 8. Bow-Tie antenna input impedance, imaginary part.

Table 2. Input impedance calculation using Zeland IE3D, quasi-static, biconical approximation and tapered transmission line methods of analysis at resonance frequency $900 \mathrm{MHz}$.

\begin{tabular}{ccc}
\hline Method of calculation & $Z_{\text {real }}$ & $Z_{\text {imag. }}$ \\
Zeland software simulation & $309.41 \Omega$ & $-9.92 \Omega$ \\
Quasi-static method & $463 \Omega$ & $-9.69 \Omega$ \\
Biconical approximation method & $489 \Omega$ & $\Omega$ \\
Tapered transmission line method & $362 \Omega$ & $-15 \Omega$ \\
\hline
\end{tabular}




\subsubsection{Analytical Method}

In this method, the universal UHF RFID frequency band from $860 \mathrm{MHz}$ to $960 \mathrm{MHz}$ is only considered. Parametric studies on Bow-Tie antenna width and length and their effect on the input impedance of the antenna are carried out. Finally, an equation which describes the input impedance as a function of geometry is obtained. IE3D software is used to calculate the input impedance of the Bow-Tie antenna as its length and width were changed from $105 \mathrm{~mm}$ to $140 \mathrm{~mm}$ and from 1 to $70 \mathrm{~mm}$, respectively. Curve fitting technique is used to obtain the best fit analytical equation; $8^{\text {th }}$ degree sum of sines for the real part of input impedance $Z_{r}$.

$$
Z_{r}=\sum_{i=1}^{N} a_{i} \sin \left(b_{i} f+c_{i}\right)
$$

where $i=1,2,3, \cdots, N$.

As stated in Equation (22) $Z_{r}$ depends on Bow-Tie antenna frequency $f$ and coefficients $a_{1}, b_{1}, c_{1}, \cdots, a_{N}, b_{N}, c_{N}$. These coefficients depend on both length and width of Bow-Tie antenna. The aforementioned coefficients are obtained by using curve fitting technique which gives the best fit equations; $8^{\text {th }}$ Fourier as given below:

$$
a_{i}(L)=x_{0}+\sum_{m=1}^{M}\left[x_{m} \cos \left(m_{a L} L\right)+X_{m} \sin \left(m_{a L} L\right)\right]
$$

where $a_{i}(L)$ is coefficient $a_{i}$ which depends on length $L$, and $m=1,2,3, \cdots, M$, coefficients $\left(x_{0}, x_{1}, X_{1}, \cdots, x_{M}, X_{M}, m_{a L}\right)$ in Equation (23) are stated in Table 3.

\begin{tabular}{|c|c|c|c|c|c|c|c|c|c|c|c|c|c|c|c|c|}
\hline & $a_{1}(L)$ & $a_{1}(W)$ & $a_{2}(L)$ & $a_{2}(W)$ & $a_{3}(L)$ & $a_{3}(W)$ & $a_{4}(L)$ & $a_{4}(W)$ & $a_{5}(L)$ & $a_{5}(W)$ & $a_{6}(L)$ & $a_{6}(W)$ & $a_{7}(L)$ & $a_{7}(W)$ & $a_{8}(L)$ & $a_{8}(W)$ \\
\hline$x_{0}$ & 487.1 & 142.4 & 82.22 & 82.86 & 32.84 & 106.7 & 48.53 & 43.93 & 63.41 & 35.6 & 19.34 & 20.83 & 9.67 & 11.24 & 5.62 & 4.172 \\
\hline$x_{1}$ & -564.3 & 9.131 & 8.121 & -24.29 & -28.61 & -4.21 & 37.72 & -33.54 & 22.27 & 4.75 & -0.9018 & $8-0.406$ & -1.52 & 0.378 & 2.22 & -9.504 \\
\hline$X_{1}$ & 172.3 & -2.447 & -33.41 & -5.241 & 23.54 & 116.4 & 57.26 & 3.844 & 5.68 & 0.646 & -1.437 & 0.66 & 0.575 & 0.194 & 1.94 & -6.313 \\
\hline$x_{2}$ & 192.5 & 3.991 & 16.5 & -1.163 & 35.98 & -83.38 & -13.63 & -0.959 & 25.62 & -5.833 & -1.348 & -0.057 & 0.784 & -0.027 & 0.323 & 15.42 \\
\hline$X_{2}$ & -150.7 & 3.416 & -9.285 & -15.87 & 21.58 & -15.4 & 51.19 & -12.27 & -31.54 & -4.235 & -0.5421 & $1-0.108$ & 0.307 & -0.112 & 3.286 & -7.714 \\
\hline$x_{3}$ & 0 & -5.273 & -45.45 & -10.21 & 0.097 & -15.65 & -62.55 & -6.174 & 0 & -3.99 & -0.1917 & $7-0.45$ & 0.082 & 0.309 & -1.88 & -1.167 \\
\hline$X_{3}$ & 0 & 0.8525 & 3.45 & -0.336 & -21.62 & 67.04 & -46.88 & -1.275 & 0 & 1.946 & -2.378 & 0.801 & -0.44 & 0.183 & 1.659 & 16.19 \\
\hline$x_{4}$ & 0 & 2.676 & -101.7 & 5.383 & 0 & 32.86 & 0 & -15.37 & 0 & -0.384 & -0.4302 & $2-0.578$ & -0.38 & -0.283 & -1.41 & -9.009 \\
\hline$X_{4}$ & 0 & 1.287 & 15.64 & -16.19 & 0 & -3.74 & 0 & -5.266 & 0 & 0.797 & -1.755 & -0.108 & 0.36 & -0.301 & 0.032 & -6.137 \\
\hline$x_{5}$ & 0 & 0 & 0 & -5.76 & 0 & 0 & 0 & 4.428 & 0 & 1.875 & 0 & -0.375 & 0 & -0.035 & -0.35 & 4.591 \\
\hline$X_{5}$ & 0 & 0 & 0 & -0.186 & 0 & 0 & 0 & -11.14 & 0 & -3.134 & 0 & 0.282 & 0 & -0.067 & -0.59 & -2.167 \\
\hline$x_{6}$ & 0 & 0 & 0 & 16.16 & 0 & 0 & 0 & -5.972 & 0 & 1.041 & 0 & -5.97 & 0 & 0 & 0 & -0.013 \\
\hline$X_{6}$ & 0 & 0 & 0 & -8.828 & 0 & 0 & 0 & -13.56 & 0 & -2.985 & 0 & -13.56 & 0 & 0 & 0 & 1.253 \\
\hline$x_{7}$ & 0 & 0 & 0 & 16.01 & 0 & 0 & 0 & 3.747 & 0 & 0 & 0 & 3.747 & 0 & 0 & 0 & 0 \\
\hline$X_{7}$ & 0 & 0 & 0 & -2.268 & 0 & 0 & 0 & -10.73 & 0 & 0 & 0 & -10.73 & 0 & 0 & 0 & 0 \\
\hline$x_{8}$ & 0 & 0 & 0 & 0 & 0 & 0 & 0 & 0 & 0 & 0 & 0 & 0 & 0 & 0 & 0 & 0 \\
\hline$X_{8}$ & 0 & 0 & 0 & 0 & 0 & 0 & 0 & 0 & 0 & 0 & 0 & 0 & 0 & 0 & 0 & 0 \\
\hline$m_{a L}$ & 0.107 & 0 & 0.333 & 0 & 0.2635 & 0 & 0.6642 & 0 & 0.2333 & 0 & 0.6642 & 0 & 0.44 & 0 & 0.199 & 0 \\
\hline$m_{a w}$ & 0 & 0.3156 & 0 & 0.3868 & 0 & 0.2635 & 0 & 0.3825 & 0 & 0.377 & 0 & 0.571 & 0 & 0.438 & 0 & 0.2146 \\
\hline
\end{tabular}

Table 3. The value of coefficients $\left(x_{0}, x_{1}, X_{1}, \cdots, x_{8}, X_{8}, m_{a L}, m_{a W}\right)$ for $a_{i}(L)$ and $a_{i}(W)$. 


$$
a_{i}(W)=x_{0}+\sum_{j=1}^{J}\left[x_{j} \cos \left(m_{a W} L\right)+X_{j} \sin \left(m_{a W} L\right)\right]
$$

where $a_{i}(W)$ is coefficient $a_{i}$ depends on width $W$, and $j=1,2,3, \cdots, J$, coefficients $\left(x_{0}, x_{1}, X_{1}, \cdots, x_{J}, X_{J}, m_{a W}\right)$ in Equation (24) are stated in Table 3.

Taking the average value of $a_{i}(L)$ and $a_{i}(W)$ to form total coefficient $a_{i}$

$$
\begin{aligned}
& a_{i}=\left(a_{i}(L)+a_{i}(W)\right) / 2 \\
& b_{i}(L)=y_{0}+\sum_{m=1}^{M}\left[y_{m} \cos \left(m_{b L} L\right)+Y_{m} \sin \left(m_{b L} L\right)\right]
\end{aligned}
$$

where $b_{i}(L)$ is coefficient $b_{i}$ depends on length $L$, and $m=1,2,3, \cdots, M$, coefficients $\left(y_{0}, y_{1}, Y_{1}, \cdots, y_{M}, Y_{M}, m_{b L}\right)$ in Equation (26) are stated in Table 4.

$$
b_{i}(W)=y_{0}+\sum_{j=1}^{J}\left[y_{j} \cos \left(m_{b W} L\right)+Y_{J} \sin \left(m_{b W} L\right)\right]
$$

where $b_{i}(W)$ is coefficient $b_{i}$ depends on width $W$, and $j=1,2,3, \cdots, J$, coefficients $\left(y_{0}, y_{1}, Y_{1}, \cdots, y_{J}, Y_{J}, m_{W}\right)$ in Equation (27) are stated in Table 4.

Taking the average value of $b_{i}(L)$ and $b_{i}(W)$ to form total coefficient $b_{i}$

\begin{tabular}{|c|c|c|c|c|c|c|c|c|c|c|c|c|c|c|c|c|}
\hline & $b_{1}(L)$ & $b_{1}(W)$ & $b_{2}(L)$ & $b_{2}(W)$ & $b_{3}(L)$ & $b_{3}(W)$ & $b_{4}(L)$ & $b_{4}(W)$ & $b_{5}(L)$ & $b_{5}(W)$ & $b_{6}(L)$ & $b_{6}(W)$ & $b_{7}(L)$ & $b_{7}(W)$ & $b_{8}(L)$ & $b_{8}(W)$ \\
\hline$y_{0}$ & 2.224 & 2.727 & 10.07 & 10.35 & 14.33 & 16.53 & 5.232 & 14.85 & 9.804 & 6.05 & 23.86 & 22.73 & 30.73 & 29.22 & 35.2 & 34.78 \\
\hline$y_{1}$ & 0.2206 & -0.015 & -0.365 & 0.1314 & -2.374 & -0.329 & -11.29 & 4.126 & 4.819 & 0.016 & -0.090 & -0.233 & 1.341 & 0.1363 & -2.03 & 0.0775 \\
\hline$Y_{1}$ & 0.2649 & 0.04 & -0.168 & -0.099 & -4.024 & -0.264 & -6.381 & -3.28 & -6.843 & -0.074 & 1.02 & -0.269 & 0.679 & 0.215 & 0.5 & 0.0458 \\
\hline$y_{2}$ & -0.035 & 0.017 & -0.485 & -0.050 & 2.651 & 0.036 & -4.621 & 1.298 & 0.273 & -0.525 & 0.548 & -0.023 & 0.213 & 0.087 & -1.2 & -0.048 \\
\hline$Y_{2}$ & 0.3481 & 0.022 & -0.385 & -0.205 & -2.496 & -0.012 & -8.753 & -2.908 & -4.645 & 0.0091 & -0.138 & 0.1081 & -0.36 & 0.1257 & 2.21 & 0.2046 \\
\hline$y_{3}$ & 0.0987 & -0.004 & 0 & 3.092 & 1.474 & -0.114 & 1.788 & -0.328 & -0.103 & 1.202 & 0.247 & 0.1593 & 0.43 & 0 & -0.3 & -0.168 \\
\hline$Y_{3}$ & -0.350 & 0.237 & 0 & 0 & 1.101 & -0.208 & -6.513 & -3.69 & -1.034 & 0.0215 & 0.342 & -0.153 & 0.009 & 0 & 3.38 & -0.18 \\
\hline$y_{4}$ & 0 & -0.27 & 0 & 0 & 0 & 0.076 & 4.761 & -1.97 & 1.299 & 0.2916 & -0.255 & -0.236 & -0.50 & 0 & 2.53 & 0 \\
\hline$Y_{4}$ & 0 & -0.059 & 0 & 0 & 0 & 0.314 & -2.185 & -1.499 & -1.783 & -0.197 & -0.170 & -0.004 & 0 & 0 & 2.96 & 0 \\
\hline$y_{5}$ & 0 & -0.031 & 0 & 0 & 0 & -0.187 & 5.06 & 0 & -1.284 & -0.091 & -1.284 & 0.033 & 0 & 0 & 0 & 0 \\
\hline$Y_{5}$ & 0 & -0.271 & 0 & 0 & 0 & 0.037 & 0.04 & 0 & -1.693 & -0.176 & -1.693 & -0.121 & 0 & 0 & 0 & 0 \\
\hline$y_{6}$ & 0 & 0 & 0 & 0 & 0 & 0.14 & 2.704 & 0 & 0 & 0.505 & 0 & -0.089 & 0 & 0 & 0 & 0 \\
\hline$Y_{6}$ & 0 & 0 & 0 & 0 & 0 & 0.22 & 1.186 & 0 & 0 & 0.2595 & 0 & -0.145 & 0 & 0 & 0 & 0 \\
\hline$y_{7}$ & 0 & 0 & 0 & 0 & 0 & 0 & 0 & 0 & 0 & -0.212 & 0 & 0 & 0 & 0 & 0 & 0 \\
\hline$Y_{7}$ & 0 & 0 & 0 & 0 & 0 & 0 & 0 & 0 & 0 & 0.277 & 0 & 0 & 0 & 0 & 0 & 0 \\
\hline$y_{8}$ & 0 & 0 & 0 & 0 & 0 & 0 & 0 & 0 & 0 & -0.338 & 0 & 0 & 0 & 0 & 0 & 0 \\
\hline$Y_{8}$ & 0 & 0 & 0 & 0 & 0 & 0 & 0 & 0 & 0 & -0.163 & 0 & 0 & 0 & 0 & 0 & 0 \\
\hline$m_{b L}$ & 0.2843 & 0 & 0.307 & 0 & 0.2673 & 0 & 0.2588 & 0 & 0.2488 & 0 & 0.2638 & 0 & 0.266 & 0 & 0.79 & 0 \\
\hline$m_{b W}$ & 0 & 0.7785 & 0 & 3.092 & 0 & 0.442 & 0 & 0.2805 & 0 & 0.339 & 0 & 0.45 & 0 & 3.129 & 0 & 0.7993 \\
\hline
\end{tabular}

$$
b_{i}=\left(b_{i}(L)+b_{i}(W)\right) / 2
$$

Table 4. The value of coefficients $\left(y_{0}, y_{1}, Y_{1}, \cdots, y_{8}, Y_{8}, m_{L}, m_{W}\right)$ for $b_{n}(L)$ and $b_{n}(W)$. 


$$
c_{i}(L)=z_{0}+\sum_{m=1}^{M}\left[z_{m} \cos \left(m_{c L} L\right)+Z_{m} \sin \left(m_{c L} L\right)\right]
$$

where $c_{i}(L)$ is coefficient $c_{i}$ depends on length $L$, and $m=1,2,3, \cdots, M$, coefficients $\left(z_{0}, z_{1}, Z_{1}, \cdots, z_{M}, Z_{M}, m_{c L}\right)$ in Equation (29) are stated in Table 5.

$$
c_{i}(W)=z_{0}+\sum_{j=1}^{J}\left[z_{m} \cos \left(m_{c W} L\right)+Z_{m} \sin \left(m_{c W} L\right)\right]
$$

where $c_{i}(W)$ is coefficient $c_{i}$ depends on width $W$, and $j=1,2,3, \cdots, J$, coefficients $\left(z_{0}, z_{1}, Z_{1}, \cdots, z_{M}, Z_{M}, m_{c W}\right)$ in Equation (30) are stated in Table 5.

Taking the average value of $c_{i}(L)$ and $c_{i}(W)$ to form total coefficient $c_{i}$

$$
c_{i}=\left(c_{i}(L)+c_{i}(W)\right) / 2
$$

The same procedure is performed to obtain an analytical equation for the imaginary part of input impedance $Z_{\text {imag. }}$

$$
Z_{\text {imag. }}=\sum_{k=1}^{K} p_{k} \sin \left(t_{k} f+s_{k}\right)
$$

\begin{tabular}{|c|c|c|c|c|c|c|c|c|c|c|c|c|c|c|c|c|}
\hline & $c_{1}(L)$ & $c_{1}(W)$ & $c_{2}(L)$ & $c_{2}(W)$ & $c_{3}(L)$ & $c_{3}(W)$ & $C_{4}(L)$ & $c_{4}(W)$ & $C_{5}(L)$ & $c_{5}(W)$ & $c_{6}(L)$ & $c_{6}(W)$ & $c_{7}(L)$ & $c_{7}(W)$ & $C_{8}(L)$ & $c_{8}(W)$ \\
\hline$z_{0}$ & -0.327 & -0.951 & -4.13 & -11.42 & 4.222 & 2.203 & 0.5044 & -8.567 & -10.41 & 47.87 & -0.867 & 0.093 & -0.66 & 1.043 & -0.23 & 3.933 \\
\hline$z_{1}$ & -0.417 & -0.034 & 5.23 & 19.44 & -3.501 & -2.937 & -0.642 & 10.73 & 7.469 & -41.5 & -1.179 & -0.298 & -0.37 & 0.6224 & 0.186 & -2.506 \\
\hline$Z_{1}$ & 0.045 & -0.052 & 2.923 & 1.246 & -0.409 & -1.76 & 1.296 & 10.73 & 19.69 & -77.16 & -0.109 & 0.239 & 1.04 & 0.123 & -1.00 & -3.066 \\
\hline$Z_{2}$ & 0.279 & 0.075 & -4.913 & -15.09 & 1.109 & 0.199 & 0.7859 & 5.143 & 11.87 & -40.15 & -1.198 & -0.038 & -0.41 & 0.0075 & -1.73 & -1.012 \\
\hline$Z_{2}$ & 0.407 & 0.0025 & 0.339 & -1.612 & -4.04 & 0.922 & 1.017 & -12.01 & -6.195 & 61.34 & -0.025 & -0.027 & 1.25 & 0.512 & 0.04 & 4.079 \\
\hline$Z_{3}$ & 0 & -0.09 & 5.503 & 10.22 & 0.197 & -0.467 & 0.907 & -9.222 & -4.506 & 53.73 & 0 & -0.085 & 0.84 & -0.246 & 0.438 & 3.169 \\
\hline$Z_{3}$ & 0 & -0.041 & -1.627 & 1.663 & 2.086 & 1.054 & -1.117 & 1.646 & -4.108 & 3.738 & 0 & 0.062 & 0.23 & 0.299 & -0.27 & -2.038 \\
\hline$Z_{4}$ & 0 & -0.023 & -2.795 & -5.582 & -1.462 & 0.375 & -0.123 & 3.006 & -0.531 & -15.5 & 0 & 0.004 & 0.08 & -0.404 & -0.38 & -2.793 \\
\hline$Z_{4}$ & 0 & 0.0428 & -0.199 & -0.858 & 1.161 & -0.225 & -1.458 & 2.409 & 1.454 & -30.97 & 0 & 0.196 & -0.58 & 0.0716 & 1.131 & -0.149 \\
\hline$Z_{5}$ & 0 & 0 & 0 & 2.274 & 0 & 0.643 & 0.2968 & 0 & 0 & -10.21 & 0 & 0.085 & 0 & -0.1213 & 0 & 1.292 \\
\hline$Z_{5}$ & 0 & 0 & 0 & 0.2532 & 0 & -0.139 & -1.51 & 0 & 0 & 14.69 & 0 & 0.137 & 0 & -0.185 & 0 & 1.067 \\
\hline$z_{6}$ & 0 & 0 & 0 & -0.826 & 0 & -0.399 & 0 & 0 & 0 & 7.441 & 0 & -0.060 & 0 & 0.0232 & 0 & -0.252 \\
\hline$Z_{6}$ & 0 & 0 & 0 & 0.0873 & 0 & -0.467 & 0 & 0 & 0 & 0.006 & 0 & -0.045 & 0 & -0.1472 & 0 & -0.634 \\
\hline$z_{7}$ & 0 & 0 & 0 & 0 & 0 & 0 & 0 & 0 & 0 & -1.216 & 0 & 0.078 & 0 & 0.1293 & 0 & 0 \\
\hline$Z_{7}$ & 0 & 0 & 0 & 0 & 0 & 0 & 0 & 0 & 0 & -1.557 & 0 & -0.056 & 0 & -0.0517 & 0 & 0 \\
\hline$Z_{8}$ & 0 & 0 & 0 & 0 & 0 & 0 & 0 & 0 & 0 & 0 & 0 & 0.109 & 0 & 0 & 0 & 0 \\
\hline$Z_{8}$ & 0 & 0 & 0 & 0 & 0 & 0 & 0 & 0 & 0 & 0 & 0 & -0.039 & 0 & 0 & 0 & 0 \\
\hline$m_{c L}$ & 0.269 & 0 & 0.668 & 0 & 0.2769 & 0 & 0.2527 & 0 & 0.1801 & 0 & 0.1818 & 0 & 0.231 & 0 & 0.267 & 0 \\
\hline$m_{c W}$ & 0 & 0.3394 & 0 & 0.2353 & 0 & 0.3374 & 0 & 0.2511 & 0 & 0.255 & 0 & 0.255 & 0 & 0.3056 & 0 & 0.2436 \\
\hline
\end{tabular}

where $k=1,2,3, \cdots, K$.

Table 5. The value of coefficients $\left(z_{0}, z_{1}, Z_{1}, \cdots, z_{8}, Z_{8}, m_{c L}, m_{c W}\right)$ for $c_{n}(L)$ and $c_{n}(W)$. 
A MATLAB program was carried out to calculate these coefficients. It is found that good accuracy is obtained when $N=M=J=K=8$.

\subsubsection{Graphical Method}

In this method both length and width are changed at the same time at resonance frequency of $900 \mathrm{MHz}$ which is within the frequency band from $860 \mathrm{MHz}$ to $960 \mathrm{MHz}$. The input impedance at resonance is calculated using IE3D software and then data is imported to matlab to plot charts as shown in Figure 9 and Figure 10. Figure 9 indicates that bow-tie antenna matched with characteristic impedance $300 \Omega$, it's input impedance can be varied from $276 \Omega$ to $336 \Omega$ depending on antenna length and width variation at fixed resonance frequency $900 \mathrm{MHz}$. Same procedure is used for the input impedance calculation but at resonance of $2.45 \mathrm{GHz}$, which also indicates antenna impedance variation from $274 \Omega$ to $432 \Omega$, Figure 10. It can be noticed that resonant input impedance can be easily identified using both aforementioned figures just by knowing length and width.

\subsection{Comparison between Input Impedance Calculated by Different Methods}

In this section the real and imaginary parts of the input impedance of the Bow-Tie antenna are calculated using IE3D simulator, CST simulator, and the adopted analytical and graphical methods for the same geometric dimensions stated before, Figure 11 and Figure 12.

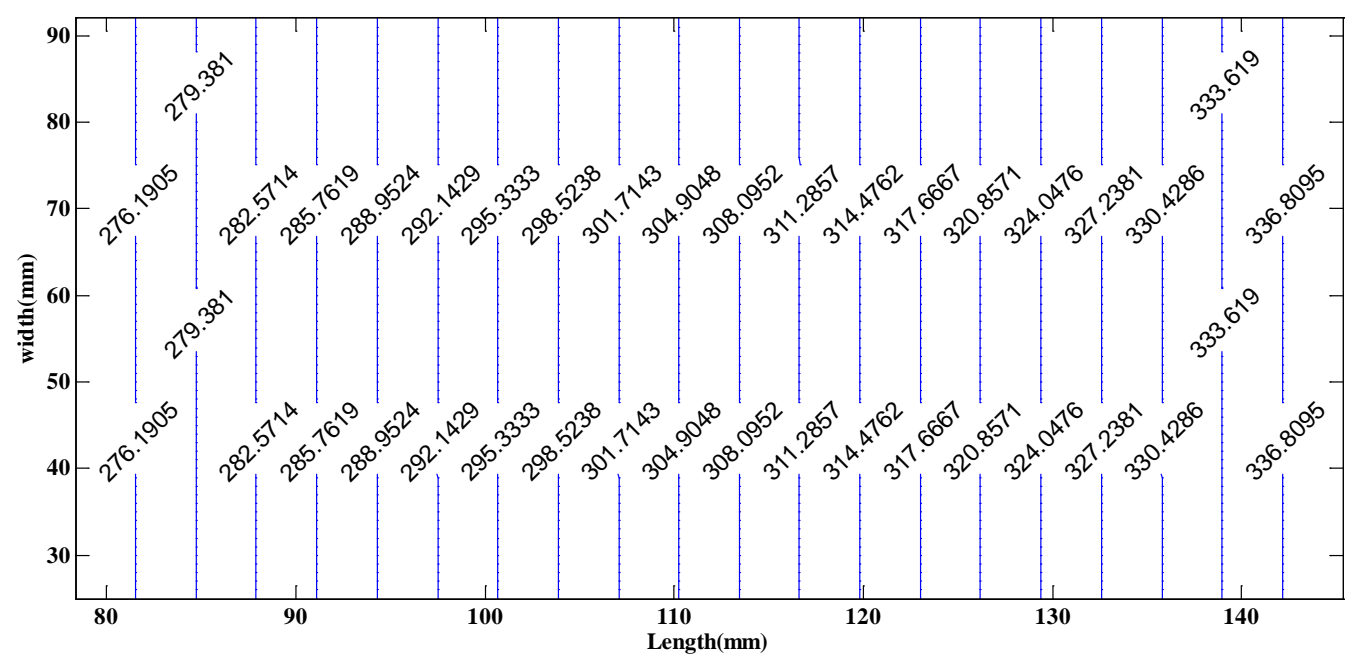

Figure 9. Bow-Tie antenna input impedance at $900 \mathrm{MHz}$.

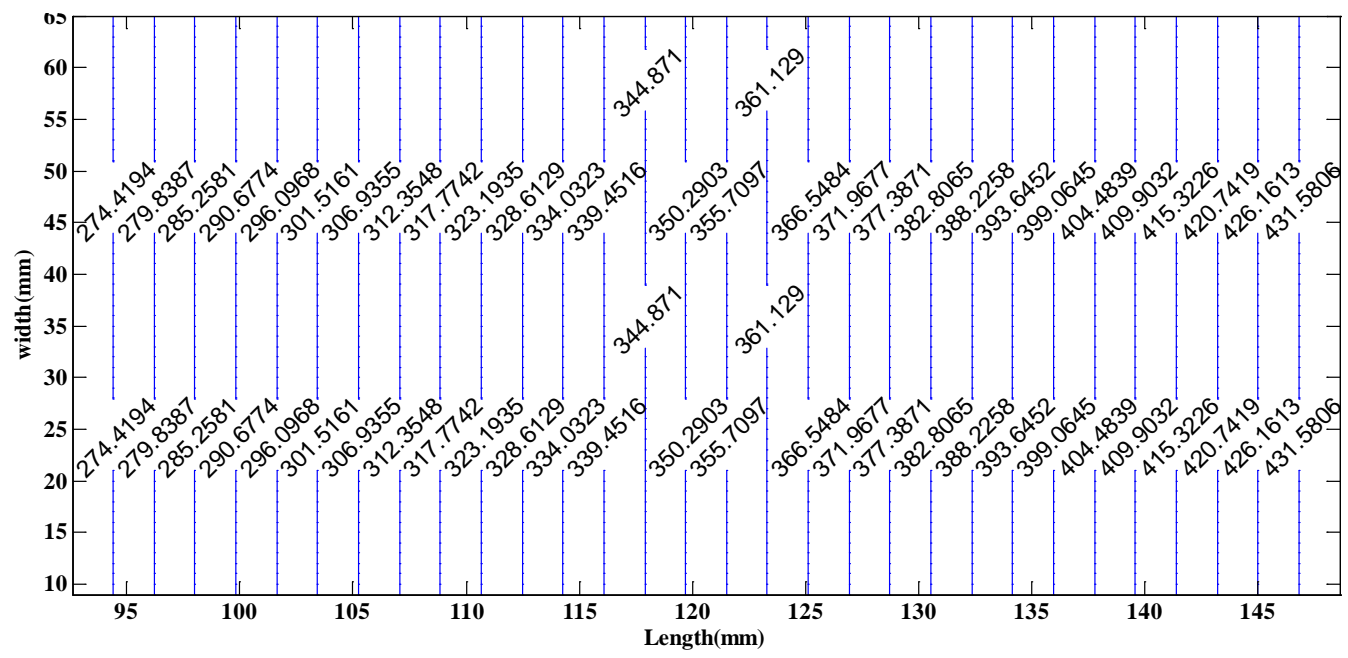

Figure 10. Bow-Tie antenna input impedance at $2.45 \mathrm{GHz}$. 


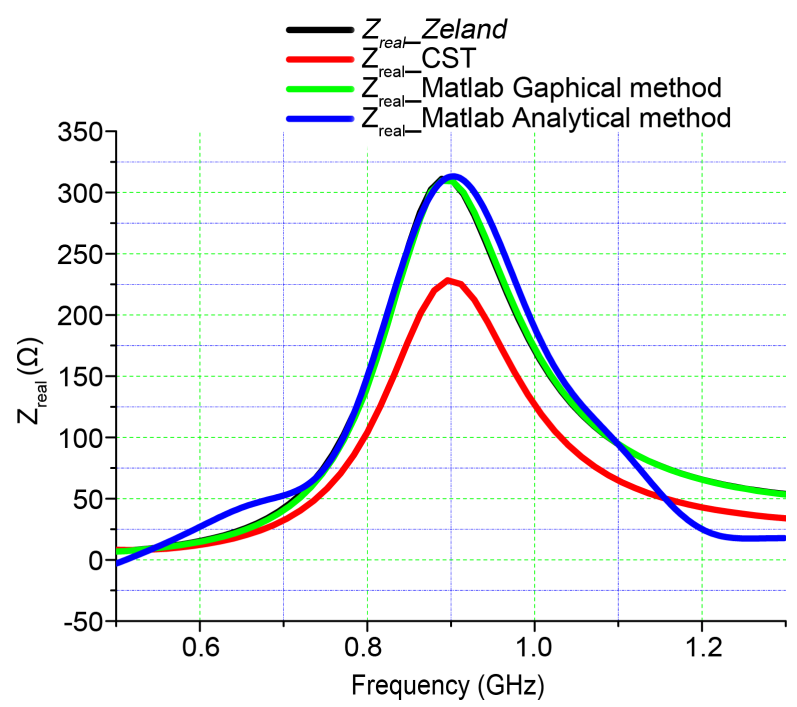

Figure 11. Bow-Tie antenna real part input impedance versus frequency using analytical, graphical, IE3D and CST methods.

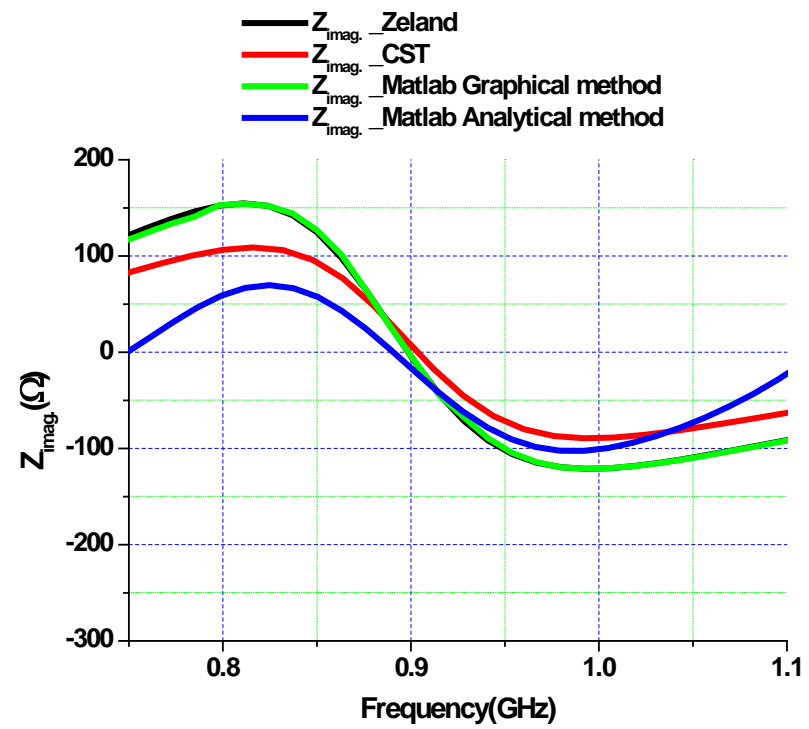

Figure 12. Bow-Tie antenna imaginary part input impedance versus frequency using analytical, graphical, IE3D and CST methods.

Referring to Figure 11 and Figure 12, it can be noticed that the proposed analytical input impedance calculation gives good result, while the proposed graphical method gives more accurate result exactly similar to Zeland IE3D, Table 6, because in this method we depend on Zeland software package in obtaining the graphical input impedance results. Also, only the frequency bandwidth from $700 \mathrm{MHz}$ to $1000 \mathrm{MHz}$ is considered that is why the Bow-Tie antenna real part input impedance is quite similar with that using graphical method except at the low frequency $(0.5-0.7 \mathrm{GHz})$ and at the high frequency (over $1 \mathrm{GHz}$ ).

\section{Conventional Bow-Tie Tag Antenna Design and Results}

A Bow-Tie Tag antenna shown in Figure 13 is designed on FR4 substrate ( $\varepsilon_{r}=4.3$, thickness $h=1.6 \mathrm{~mm}$, and $\tan (\delta)=0.02$ ). Its dimensions, length $L=56.77 \mathrm{~mm}$ and width $w=40 \mathrm{~mm}$ are determined using gometrical method design curve shown in Figure 14 as discussed in Section 2.4.2. The antenna is designed to achieve a conjugate matching to chip input impedance model Monza $5 Z_{\text {chip }}=15.05-j 163.91 \Omega$ at $900 \mathrm{MHz}$ within operating frequency extends from $860 \mathrm{MHz}$ to $960 \mathrm{MHz}$. Figure 14 indicates that antenna impedance chart curve 
Table 6. Input impedance calculation at resonance frequency $900 \mathrm{MHz}$ using Zeland IE3D, CST, analytical and graphical proposed methods.

\begin{tabular}{ccc}
\hline Method of calculations & $\boldsymbol{Z}_{\text {real }}$ & $\boldsymbol{Z}_{\text {imag. }}$ \\
\hline Zeland software simulation & $309.41 \Omega$ & $-9.92 \Omega$ \\
CST simulator & $228.24 \Omega$ & $-16.02 \Omega$ \\
Analytically proposed method & $312.89 \Omega$ & $-14.2 \Omega$ \\
Graphically proposed method & $309.2 \Omega$ & $-9.378 \Omega$ \\
\hline
\end{tabular}

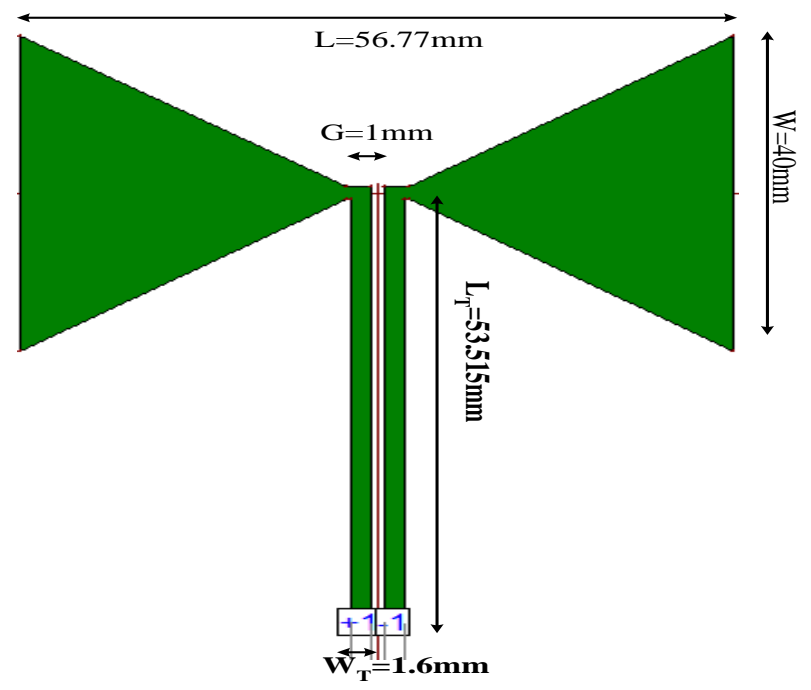

Figure 13. Bow-Tie Tag antenna geometry using Zeland IE3D.

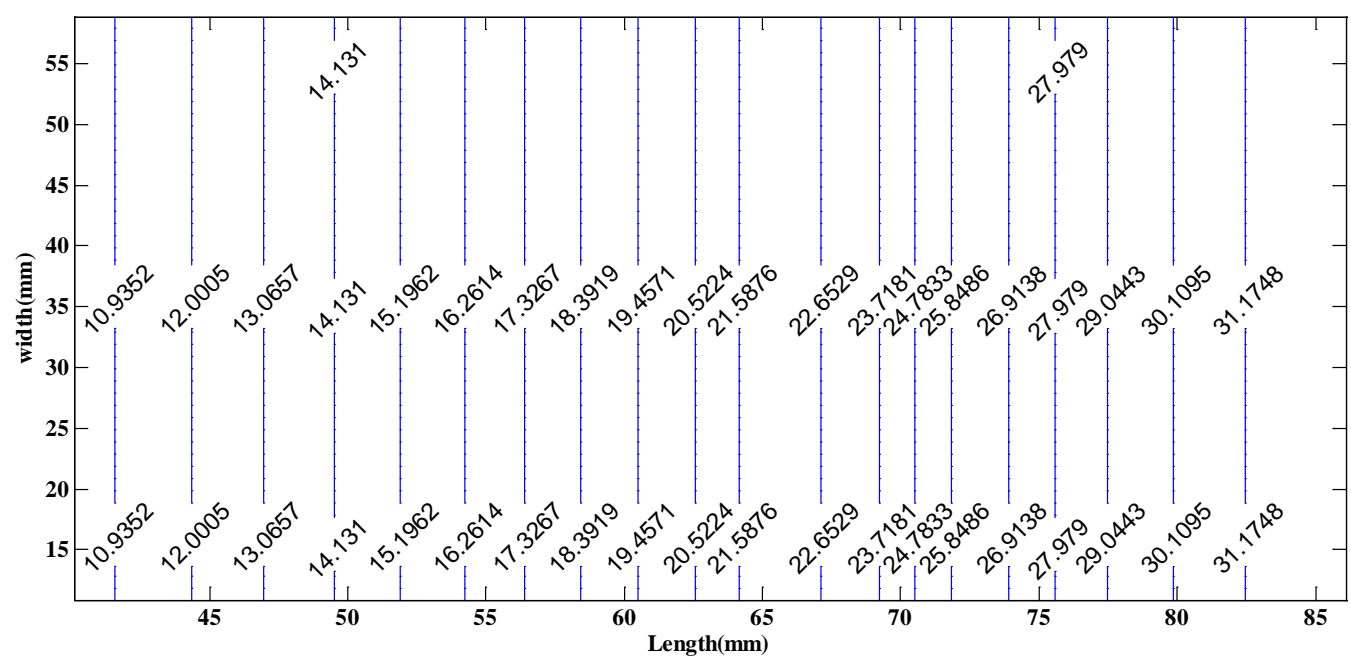

Figure 14. Bow-Tie Tag antenna input impedance, real part at $900 \mathrm{MHz}$.

varies from $10 \Omega$ to $32 \Omega$ according to antenna dimensions which can cover the chip input impedance variation from $16.47-j 171.4 \Omega$ at $860 \mathrm{MHz}$ to $13.24-j 153.8 \Omega$ at $960 \mathrm{MHz}$, respectively, Figure 15 . The real and imaginary parts of input impedance of the antenna are then computed using analytical method Equation (22) and Equation (32), Figure 16. The structure is simulated using Zeland IE3D.

The Bow-Tie antenna reflection coefficient $\left|S_{11}\right|$ as shown in Figure 17 is $-23.161 \mathrm{~dB}$ at $899 \mathrm{MHz}$. The antenna bandwidth extends from $889 \mathrm{MHz}$ to $912 \mathrm{MHz}$ for $\left|S_{11}\right|=-10 \mathrm{~dB}$, which is considered as a narrow band 


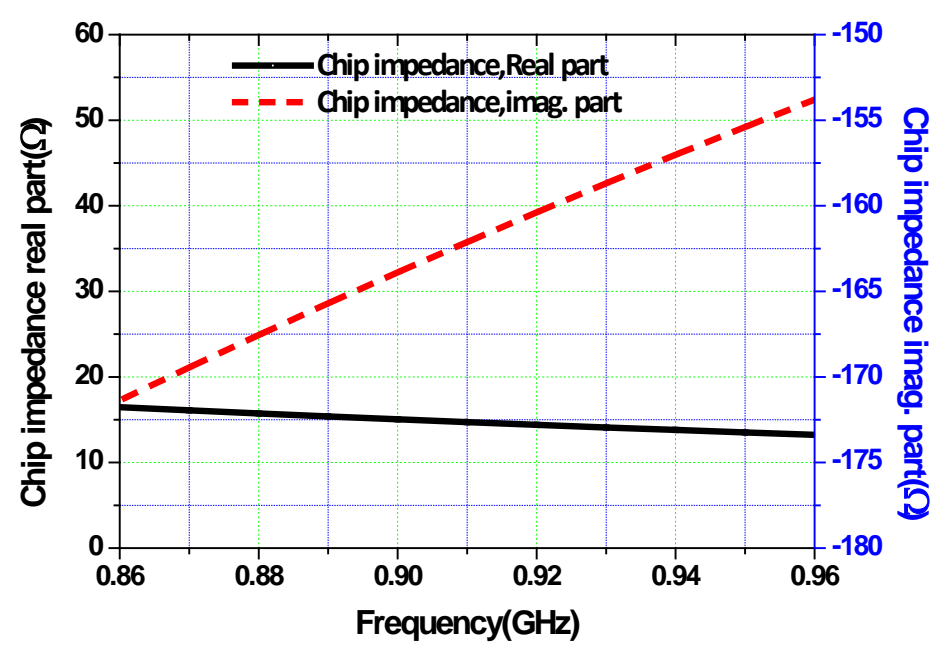

Figure 15. Chip input impedance versus frequency.

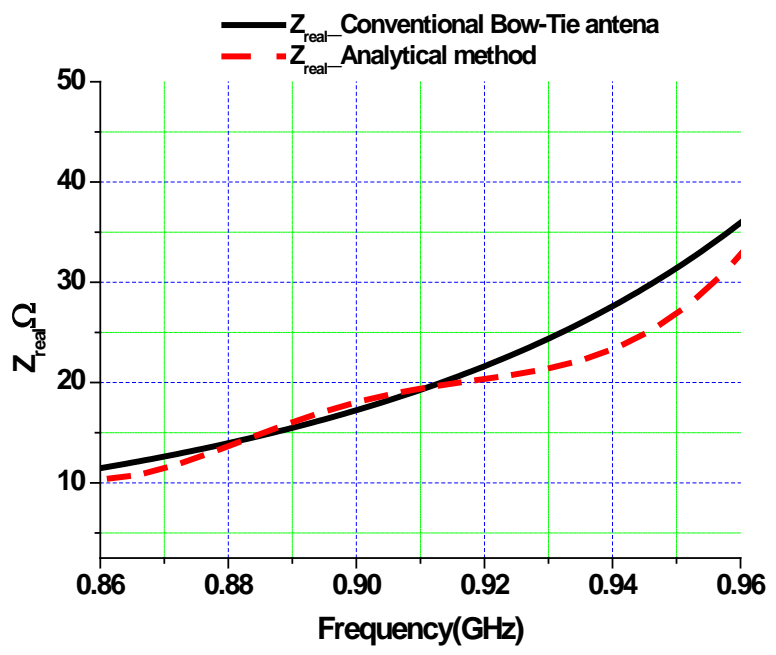

(a)

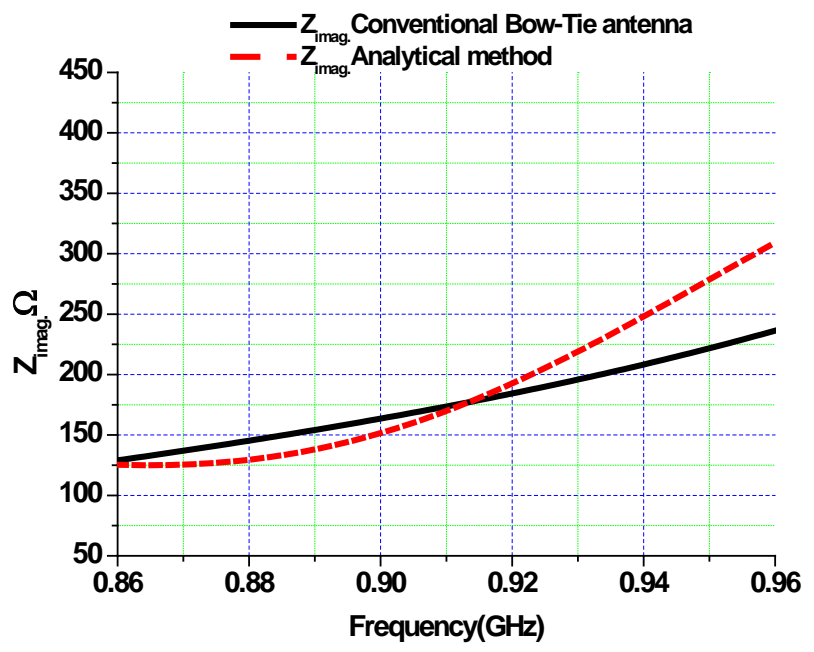

(b)

Figure 16. Tag input impedance using IE3D, and analytical method.

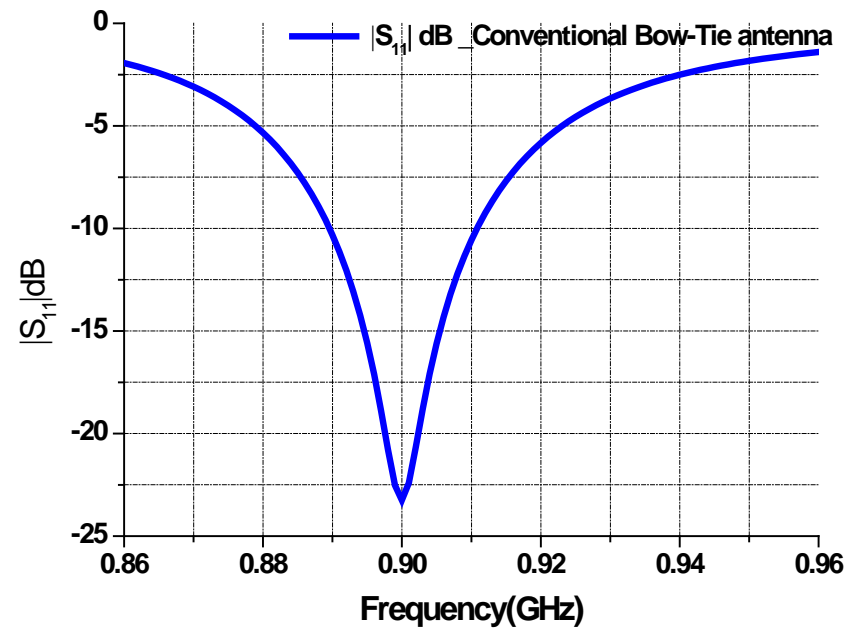

Figure 17. Bow-Tie antenna simulated reflection coefficient $\left|S_{11}\right|$ versus frequency. 
as compared to the universal bandwidth. The simulated input impedance $Z_{\text {antenna }}$ using IE3D method as shown in Figure 16 is $17.22+j 163.44 \Omega$, which indicates that the tag antenna achieves a good conjugate matching with the chip at this frequency.

The bow-tie antenna input impedance as shown in Figure 16 is $17.31+j 163.62 \Omega$ at $900 \mathrm{MHz}$. For more accurate perfectly matching to chip input impedance result and to minimize the feeding line length, we intended to use T-matched circuit. Referring to Figure 18, the input impedance of a planar dipole of length $l$ can be changed by introducing a centered short-circuited stub. The antenna source is connected to a second dipole of length $a$, placed at a close distance $b$ from the first and larger one. The electric current distributes along the two main radiators depends on the size of their transverse sections. It can be proved, that the impedance at the source point is given by [15]:

$$
\begin{aligned}
& Z_{\text {in }}=\frac{2 Z_{t}(1+\alpha)^{2} Z_{A}}{2 Z_{t}+(1+\alpha)^{2} Z_{A}} \\
& Z_{t}=j Z_{o} \tan \left(\frac{k a}{2}\right)
\end{aligned}
$$

where $Z_{t}$ is the input impedance of the short-circuit stub formed by the T-match conductors and part of the dipole.

$$
\begin{aligned}
& Z_{o}=\frac{\eta}{\pi} \cosh ^{-1}\left(\frac{b / 2}{\sqrt{r_{e} r_{e}^{\prime}}}\right) \\
& r_{e}=0.25(2 w) \\
& r_{e}^{\prime}=0.25\left(2 w^{\prime}\right)
\end{aligned}
$$

where $Z_{o}$ is the characteristic impedance of the two-conductor transmission line with spacing $b, Z_{A}$ is the dipole impedance taken at its center in the absence of the T-match connection, and $r_{e}, r_{e}^{\prime}$ are the equivalent radii of the dipole and of the matching stub, supposed to be planar traces.

$$
\alpha=\frac{\cosh ^{-1}\left(\frac{v^{2}-u^{2}+1}{2 v}\right)}{\cosh ^{-1}\left(\frac{v^{2}+u^{2}-1}{2 u v}\right)}
$$

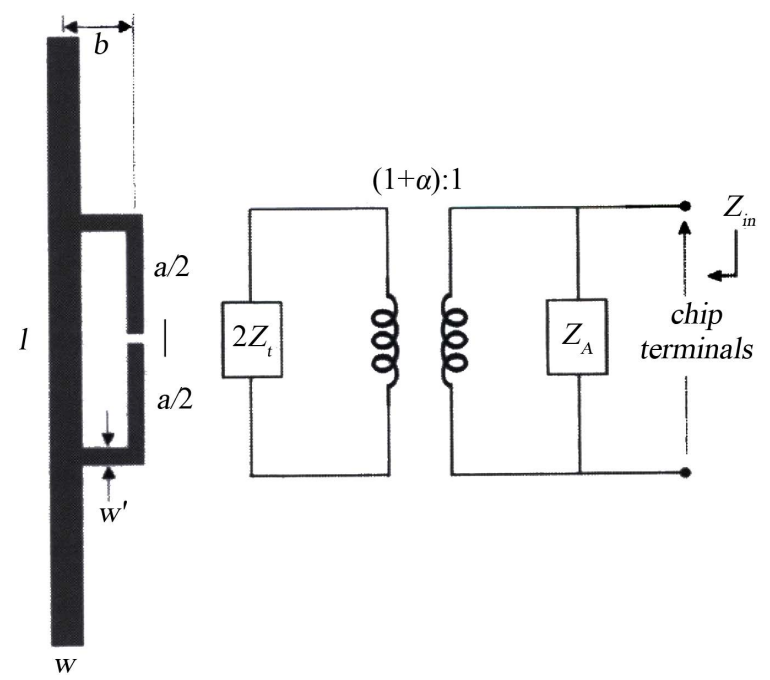

Figure 18. T-matched configuration for planar dipoles and equivalent circuit where the impedance step-up ratio $(1+\alpha)$ is related to the conductors' cross-sections [15]. 


$$
\begin{aligned}
& u=\frac{w}{w^{\prime}} \\
& v=\frac{b}{0.25\left(2 w^{\prime}\right)}
\end{aligned}
$$

where $\alpha$ is the current division factor between the two conductors. The geometrical parameters, $a, b$, and the trace's width, $w^{\prime}$, can be adjusted to match the complex chip impedance, $Z_{c h i p}$. For simplicity, we define two new aspect ratio terms, $a / l$ as second dipole length to first dipole length and $b / 2 w$ as distance between first and second dipole to total strip width, respectively.

\section{Modified Bow-Tie Antenna Design and Results:}

The proposed modified shape Bow-Tie antenna is shown in Figure 19, As stated in section 3 that bandwidth of conventional bow-tie antenna is so narrow to covers RFID band, we decided to insert slots on bow-tie antenna so as to increase it's bandwidth. Also, a T-matched circuit, [15] is used for matching enhancement purpose. The T-matched circuit is designed by applying Equation (33) on the bow-tie antenna, Figure 13 with input impedance of $17.31+j 163.62 \Omega$ at $900 \mathrm{MHz}$ and $u=w / w^{\prime}=2$, an impedance chart for the T-matched circuit as shown in Figure 20 can be plotted. As a starting point $b / 2 w=3$ and $a / l=0.2$ are chosen which from Figure 20 gives total input impedance of approximately $11.5+j 163.8 \Omega$. Then using the IE3D simulator both $b / 2 w$ and $a / l$ are optimized to be 2.4 and 0.17 , respectively.

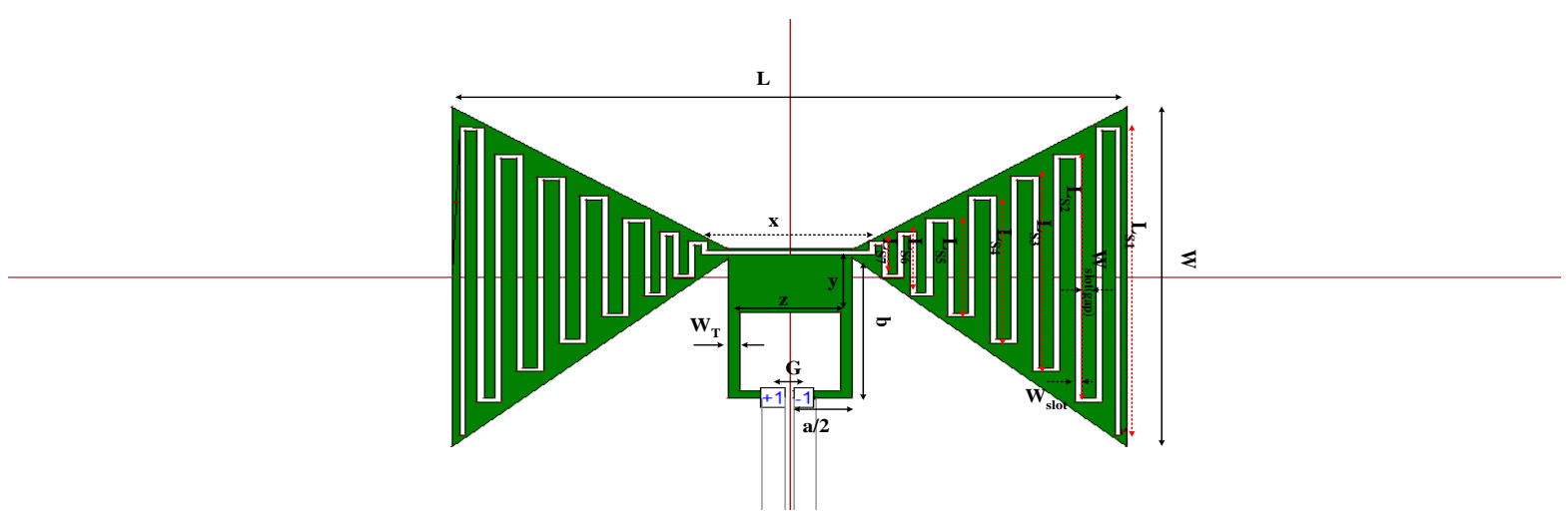

Figure 19. Modified shape Bow-Tie antenna with T-matched circuit and slots.

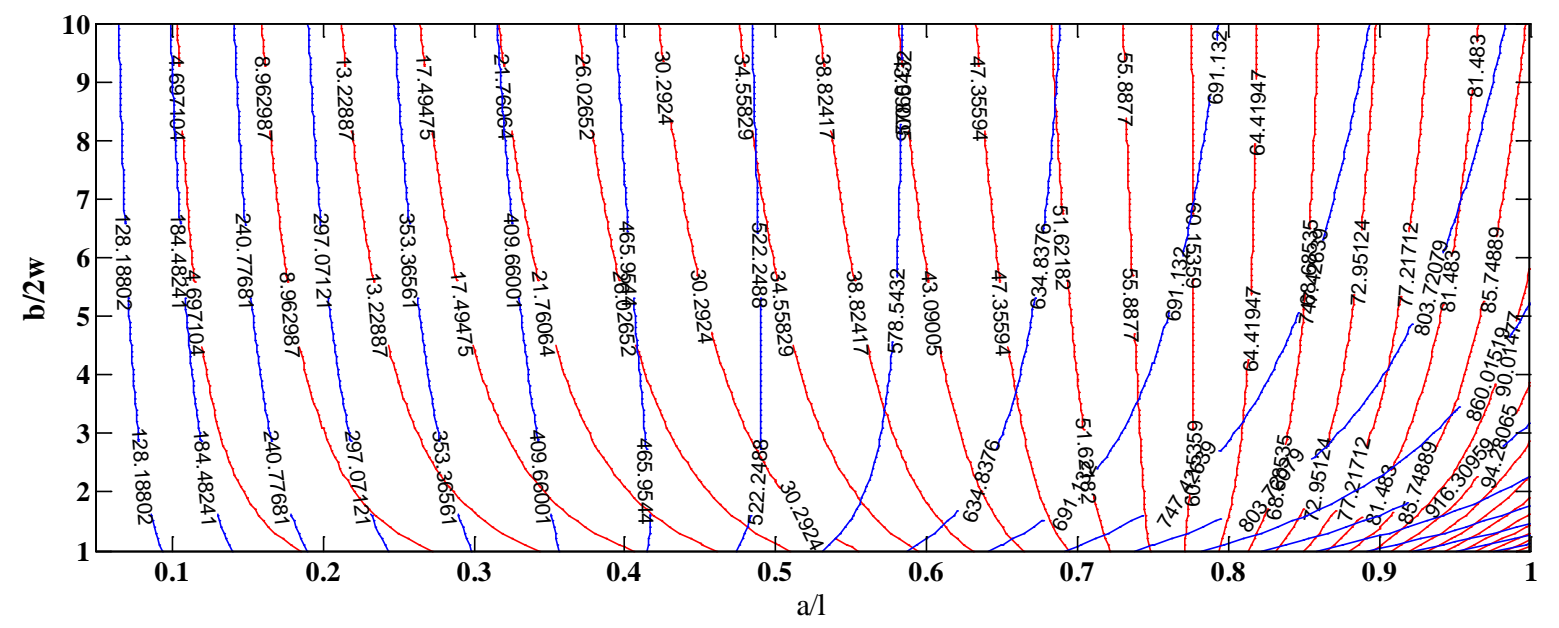

Figure 20. T-matched circuit chart for conventional bow-tie antenna with $17.31+j 163.62 \Omega$ input impedance, $u=w / w^{\prime}=2$ at $f=900 \mathrm{MHz}$. 


\subsection{T-Matched Circuit Parameters Effect on Antenna Bandwidth and Matching}

The dimensions of the modified bow-tie antenna are given in Table 7. The T-matched height $y$-parameter is varied starting from $6 \mathrm{~mm}$ to $8 \mathrm{~mm}$, other dimension, Table 7 are kept at the same values, and the simulations were carried out, Figure 21(a). It is quite clear at $y=7 \mathrm{~mm}$ the antenna can achieves acceptable matching and

Table 7. Modified Bow-Tie antenna with T-matched and slots dimensions.

\begin{tabular}{|c|c|c|c|c|c|c|c|c|c|c|}
\hline \multirow{2}{*}{ Bow-Tie } & $L$ & $W$ & $G$ & & & & & & & \\
\hline & $71.42 \mathrm{~mm}$ & $45 \mathrm{~mm}$ & $1 \mathrm{~mm}$ & & & & & & & \\
\hline \multirow{2}{*}{ T-matched } & $W_{T}$ & $a / 2$ & $b$ & $y$ & $Z$ & & & & & \\
\hline & $1 \mathrm{~mm}$ & $6.12 \mathrm{~mm}$ & $18.54 \mathrm{~mm}$ & $7 \mathrm{~mm}$ & $10.68 \mathrm{~mm}$ & & & & & \\
\hline \multirow{2}{*}{ Slots } & $L_{S 1}$ & $L_{S 2}$ & $L_{S 3}$ & $L_{S 4}$ & $L_{S 5}$ & $L_{S 6}$ & $L_{S 7}$ & $W_{\text {slot }}$ & $W_{\text {slot(gap) }}$ & $X$ \\
\hline & $40.85 \mathrm{~mm}$ & $32.24 \mathrm{~mm}$ & $25.29 \mathrm{~mm}$ & $19 \mathrm{~mm}$ & $12.5 \mathrm{~mm}$ & $8 \mathrm{~mm}$ & $5.05 \mathrm{~mm}$ & $0.6 \mathrm{~mm}$ & $1.6 \mathrm{~mm}$ & $17.1 \mathrm{~mm}$ \\
\hline
\end{tabular}

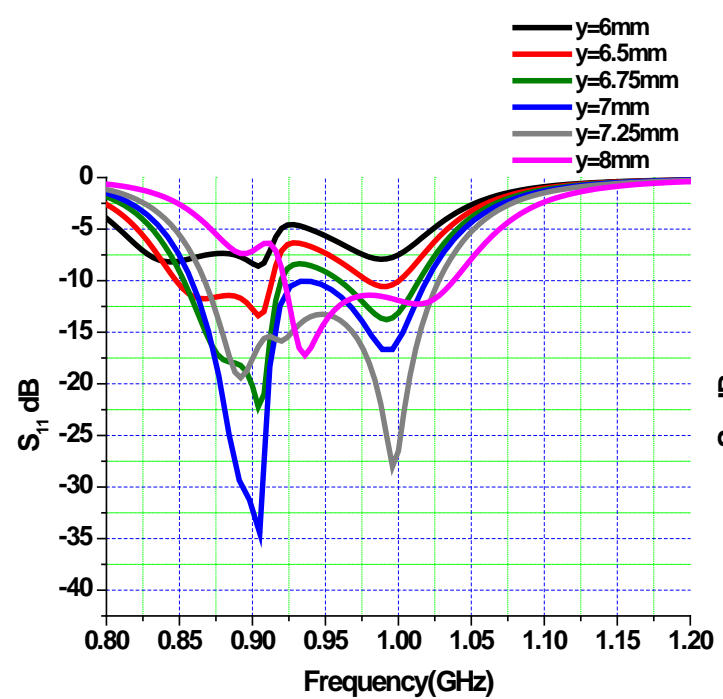

(a)

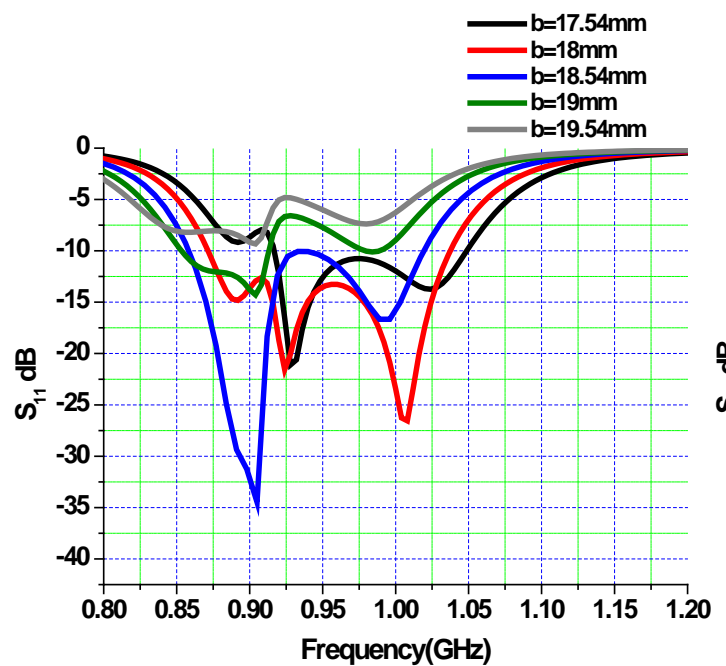

(c)

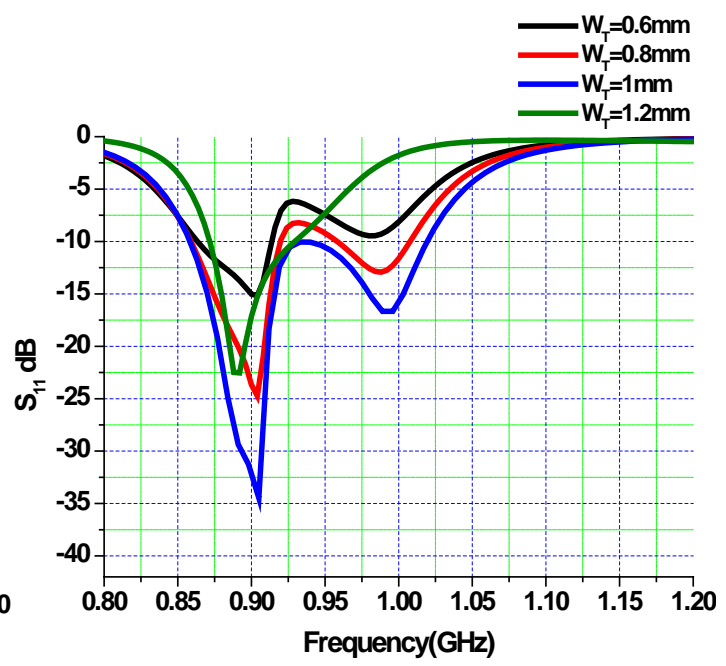

(b)

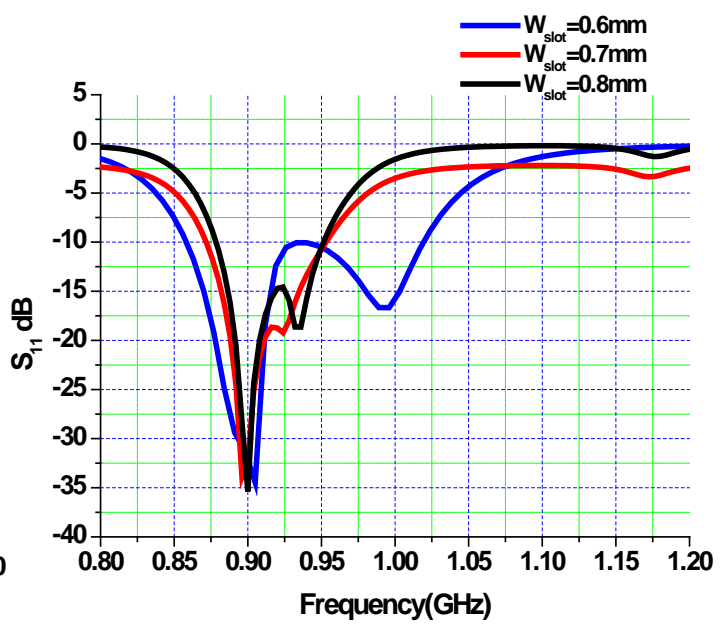

(d)

Figure 21. Modified Bow-Tie antenna reflection coefficient versus frequency at different values for both T-matched circuit and slot dimensions. 
bandwidth, below and above this value both matching and bandwidth are degraded. On the same manner $W_{T}$-parameter is varied starting from $0.6 \mathrm{~mm}$ to $1.2 \mathrm{~mm}$. It can be noticed from Figure 21(b) that as $W_{T}$ value increases, both antenna matching and bandwidth are enhanced increase until $W_{T}$ reaches $1 \mathrm{~mm}$ after that both matching and bandwidth are degraded. Also, for b-parameter which is varied from $17.54 \mathrm{~mm}$ to $19.54 \mathrm{~mm}$, Figure 21(c), good results occurs at $b=18.54 \mathrm{~mm}$.

\subsection{Slot Dimensions Effect on Antenna Bandwidth and Matching}

By changing the value of slot width $W_{\text {slot }}$ from $0.6 \mathrm{~mm}$ to $0.8 \mathrm{~mm}$, Figure 21 (d). It can be noticed that slot width is inversely proportional with antenna matching performance and bandwidth, as it decreases they increase, so good result achieved at $W_{\text {slot }}=0.6 \mathrm{~mm}$. The results are compared with conventional one, Table 8 . The obtained bandwidth is extended from $859 \mathrm{MHz}$ to $1.02 \mathrm{GHz}$, which indicates that the antenna achieves a wide bandwidth that covers the chip operating frequency, Figure 22. The antenna input impedance $Z_{\text {antenna }}$ is $15.38+j 163.7 \Omega$ which has a good matching to chip impedance $Z_{\text {chip }}=15.05-j 163.91 \Omega$ at frequency $900 \mathrm{MHz}$.

Table 8. RFID Tag conventional and modified Bow-Tie RFID tag antenna results.

\begin{tabular}{ccc}
\hline Results & Conventional Bowtie antenna & Modified Bowtie antenna with T-matched and slots \\
\hline Resonant frequency & $899 \mathrm{MHz}$ & $901 \mathrm{MHz}$ \\
$S_{11}$ & $-23.161 \mathrm{~dB}$ & $-35.28 \mathrm{~dB}$ \\
$Z_{\text {chip }}$ & $17.22+j 163.44 \Omega$ & $15.05-j 163.91 \Omega$ at $f=900 \mathrm{MHz}$ \\
$Z_{\text {antenna }}$ & & $15.38+j 163.7 \Omega$ \\
Standard bandwidth & $889 \mathrm{MHz}$ & $859 \mathrm{MHz}$ \\
$f_{\text {min }}$ at $S_{11}=-10 \mathrm{~dB}$ & $912 \mathrm{MHz}$ & $1.02 \mathrm{GHz}$ \\
$f_{\text {max }}$ at $S_{11}=-10 \mathrm{~dB}$ & & \\
Fractional bandwidth & $2.55 \%$ & $18 \%$ \\
$=\frac{f_{\max }-f_{\min } \times 100 \%}{f}$ & $660 \mathrm{MHz}$ & \\
Reading range $(\mathrm{m})$ & $2.134 \mathrm{dBi}$ & $5.9 \mathrm{~m}$ \\
Directivity & $-8.99 \mathrm{dBi}$ & $2.81 \mathrm{dBi}$ \\
Gain & $69.86 \%$ & $-9.7 \mathrm{dBi}$ \\
Radiation efficiency & $34.9 \%$ & $56.12 \%$ \\
Conjugate match efficiency & & $28.06 \%$ \\
\hline
\end{tabular}

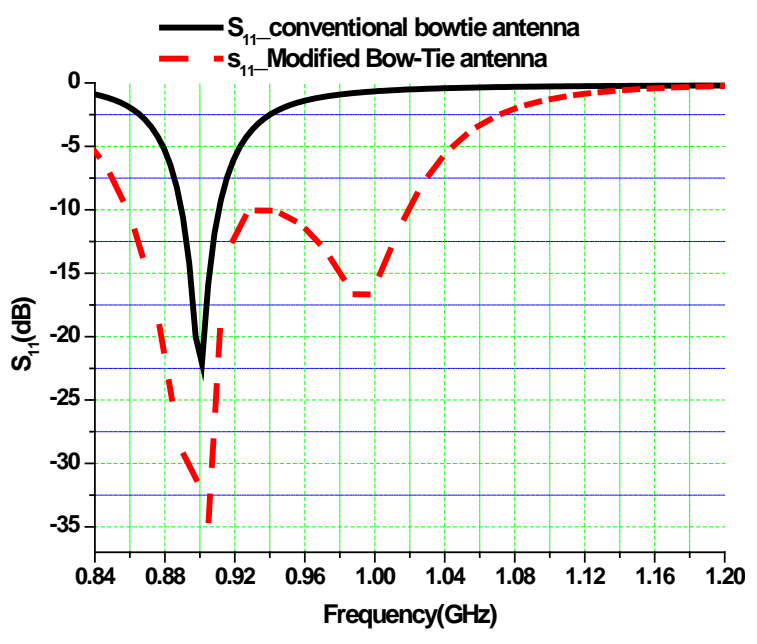

Figure 22. Reflection coefficient versus frequency for both conventional and modified Bow-Tie antenna. 
It can be noticed from Figure 22 that due to the presence of the slot, a second resonant frequency of $995 \mathrm{MHz}$ can be properly excited close to the fundamental mode. The ratio of the frequency of the two modes is made low enough to realize a wideband operation thus able to cover the entire UHF band [16]. The reading range of conventional and modified Bow-Tie tag antennas [17] with readers able to transmit at maximum power $P_{E I R P}=4$ watt for most of that bandwidth, $P_{\text {chip }}=-20 \mathrm{dBm}$ [18], $Z_{\text {chip }}$ and $Z_{\mathrm{A}}$ is shown in Figure 23.

The maximum directivity for modified Bow-Tie antenna increased to $3.3 \mathrm{dBi}$, as the electrical path has been increased. It can be indicated from Figure 19 that the existence of slots in the modified Bow-Tie antenna increases the bandwidth. For RFID applications, the antenna efficiency and antenna gain defined by IE3D may not be useful as stated in Table 8 because RFID devices behave more like constant voltage sources. For constant voltage sources, it is required to achieve conjugate matching for best efficiency [15] [19]. The current distribution for both conventional and modified bow-tie antennas are shown in Figure 24. The arrows in Figure 24(a) and Figure 24(b) indicates the average current density path through the antennas where their lengths indicate the amplitude which is of same magnitude for both antenna sides but with $180^{\circ}$ out of phase, as well known for the dipoles shapes.

The simulated coplanar and cross polarization radiation pattern of both conventional and modified bow-tie antennas are shown in Figure 25(a) and Figure 25(b). In this figure, the $E_{\text {theta }}$-field is the co-polar component,

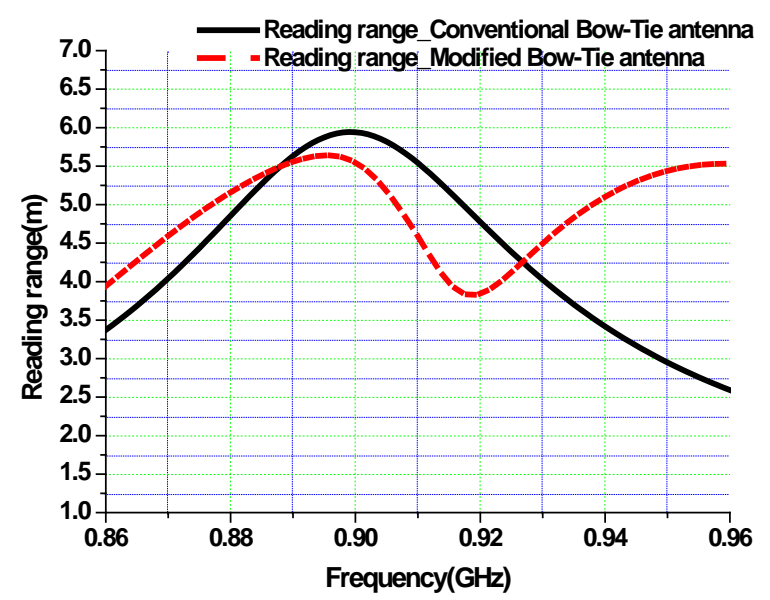

Figure 23. Reading range versus frequency for both conventional and modified Bow-Tie antenna.

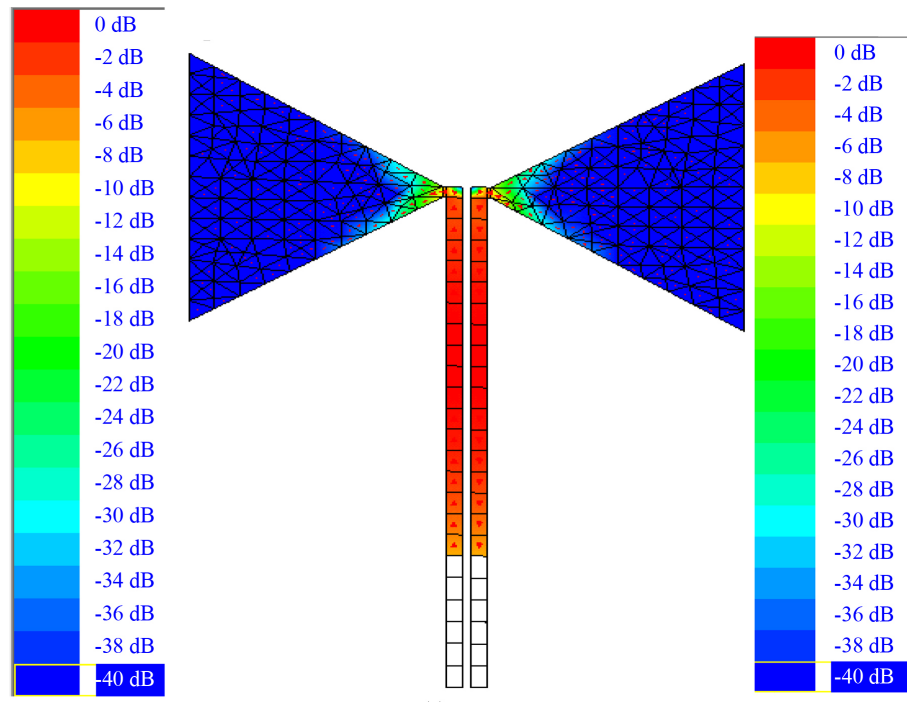

(a)

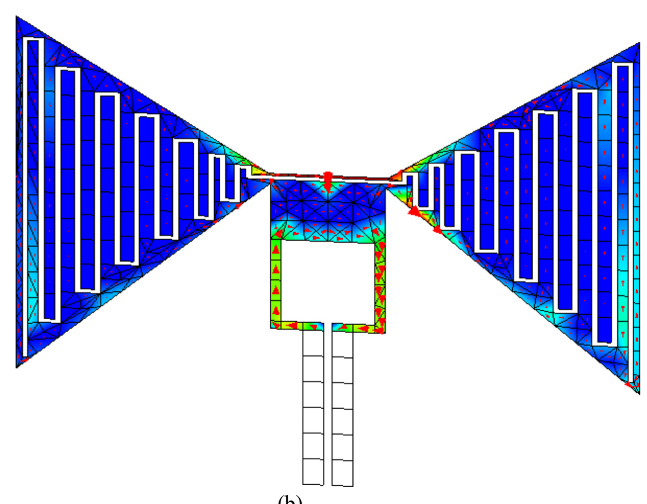
(b)

Figure 24. Current distribution for both conventional and modified Bow-Tie antenna. (a) Conventional Bow-Tie antenna. (b) Modified Bow-Tie antenna. 
and the $E_{p h i}$-field is the cross-polar component. These patterns show that the designed antenna provides linear polarization with a cross polarization level about $-30.3 \mathrm{dBi}$ lower than the co-polarization level $-8.9 \mathrm{dBi}$ for conventional bow-tie antenna and about $-27.4 \mathrm{dBi}$ lower than the co-polarization level $-10.29 \mathrm{dBi}$ for modified bow-tie antenna.

Figure 26 shows the radiation pattern of both conventional and modified bow-tie antennas which is almost omnidirectional at the H-plane and figure of eight at the E-plane that is suitable for the RFID surveillance application

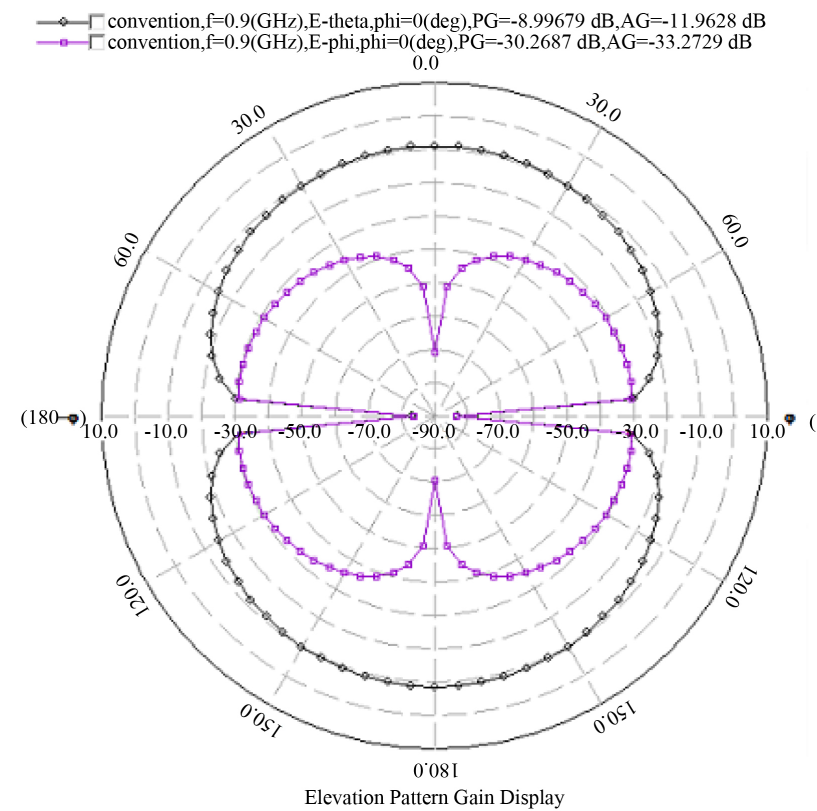

(a)

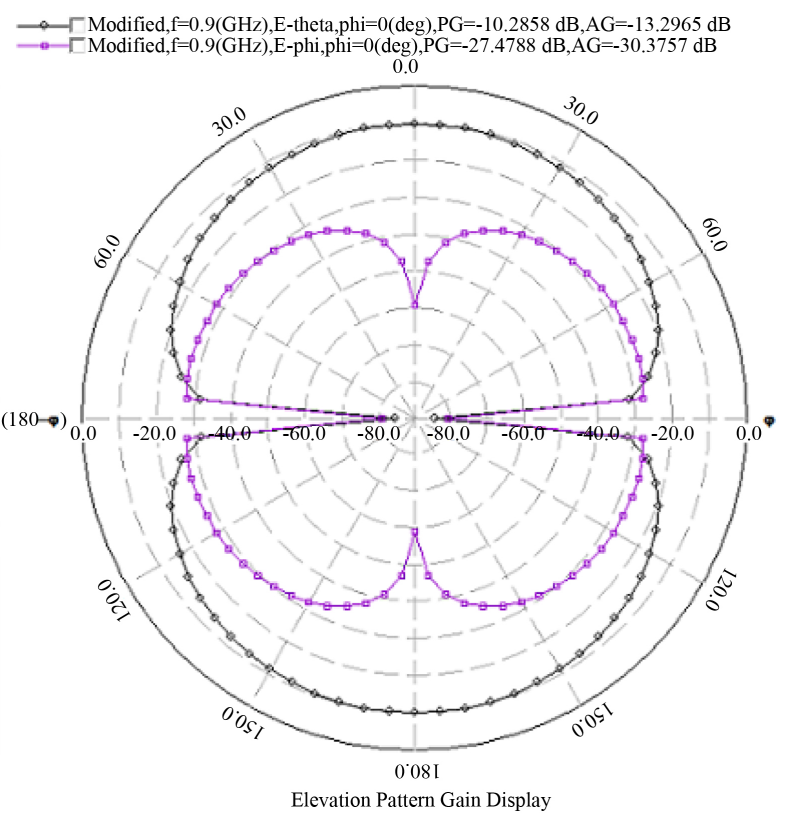

(b)

Figure 25. Co-planar and cross polarization for both conventional and modified Bow-Tie antenna. (a) Conventional BowTie antenna; (b) Modified Bow-Tie antenna.
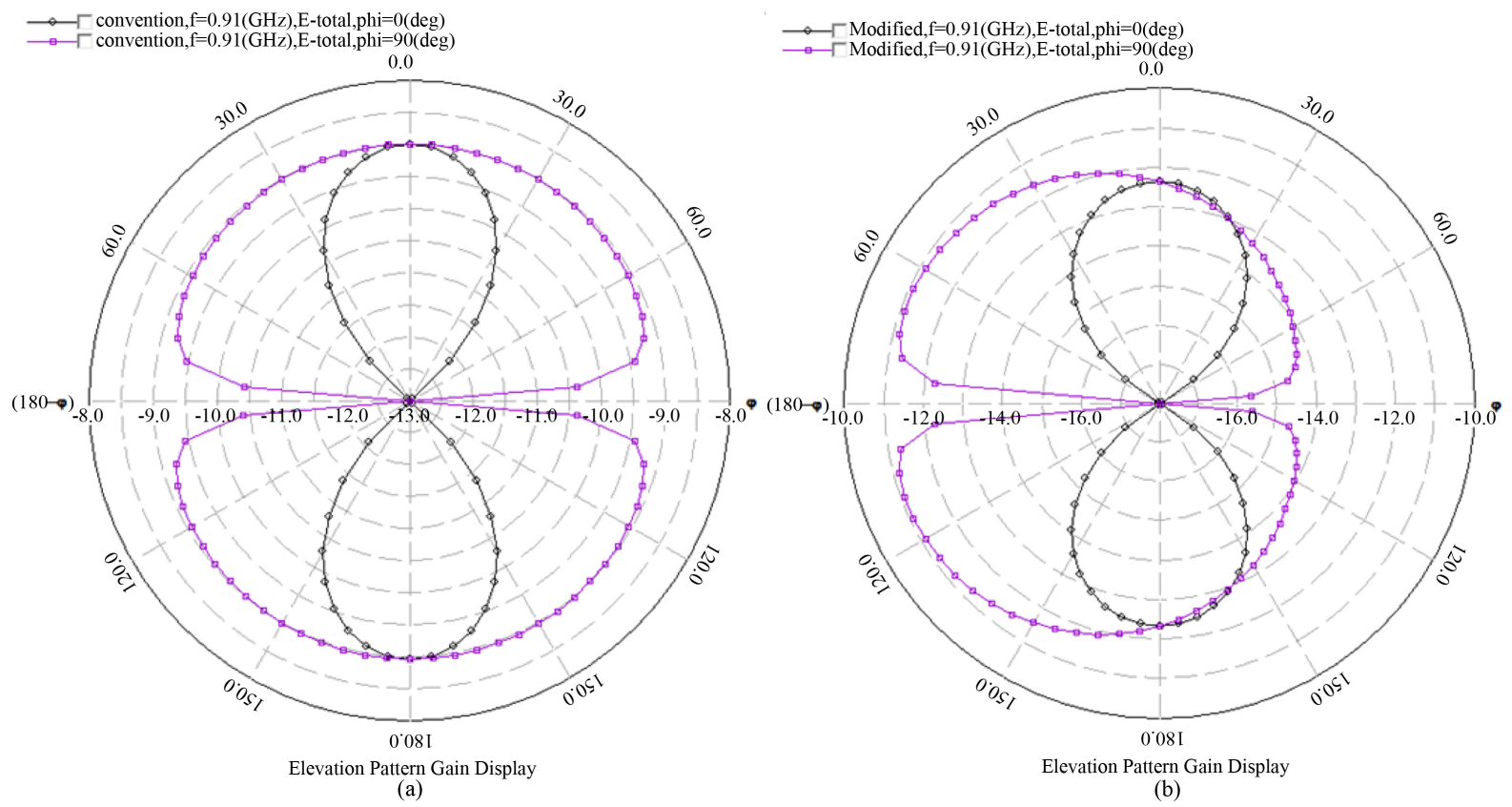

Figure 26. Radiation pattern of conventional and modified Bow-Tie antenna at $900 \mathrm{MHz}$. (a) Conventional Bow-Tie antenna; (b) Modified Bow-Tie antenna. 
[15]. The design procedure is given by the flow chart, Figure 27, where the proposed graphical method is used to find the initial geometry of the Bow-Tie antenna. Analytical method is used to calculate the antenna input impedance. IE3D simulator is used to confirm the result. If the required antenna bandwidth and required antenna matching to chip impedance are achieved, the antenna design is finished else a modification is needed and the result again has to be confirmed with IE3D simulator.

\section{Fabrication and Measurements}

The proposed conventional and modified bow-tie antennas were fabricated on FR4 substrate ( $\varepsilon_{r}=4.3$, thickness $h=1.6 \mathrm{~mm}, \tan (\delta)=0.02)$ as shown in Figure 28 and Figure 29. Input impedance of both conventional and modified proposed antennas were measured using the vector network analyzer (VNA HP8719ES) by measuring the half of the structure over ground plane and multiply the resultant input impedance by two, also $\left|S_{11}\right| \mathrm{dB}$ were calculated for both antennas [15] as shown in Figure 30 and Figure 31. As indicated, there is big difference between the simulated and the measured results. This difference is due to the air layer which was presented

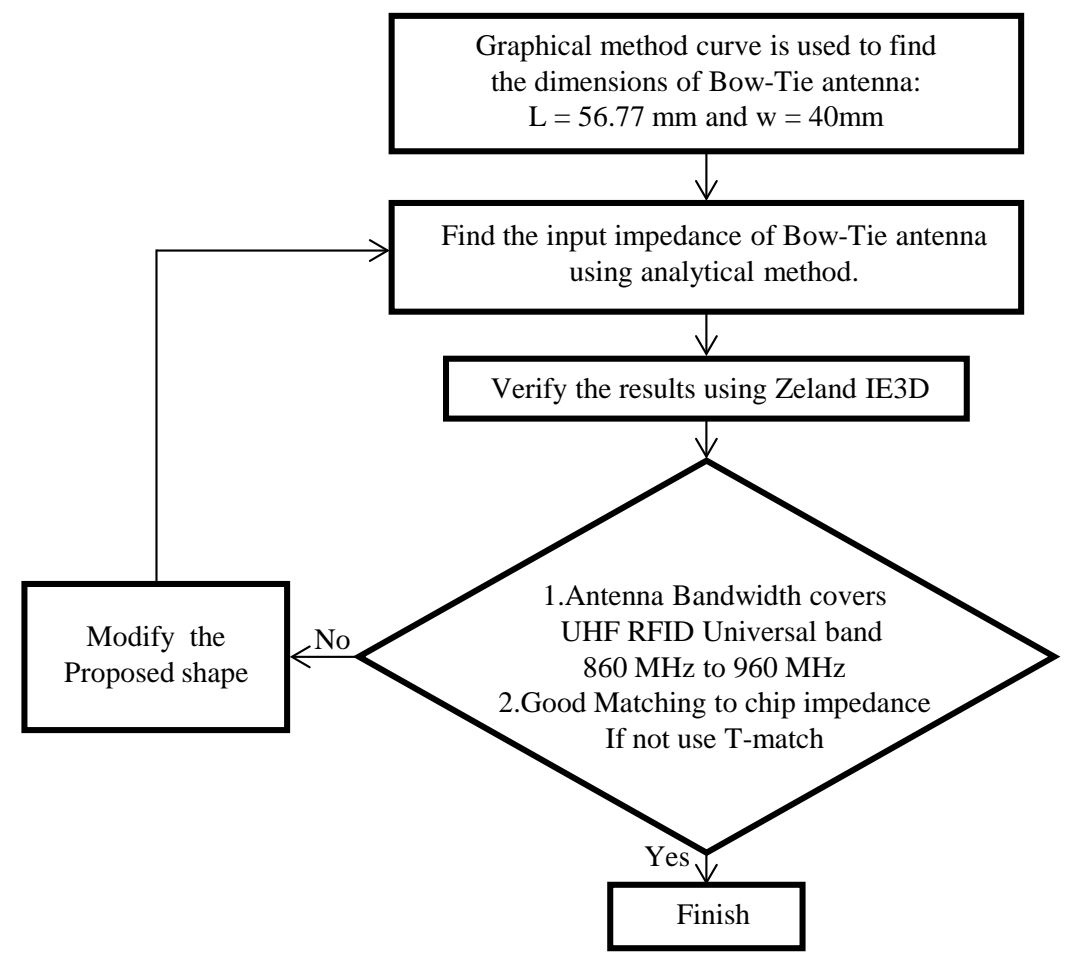

Figure 27. Flow chart of the design procedure of Bow-Tie antenna

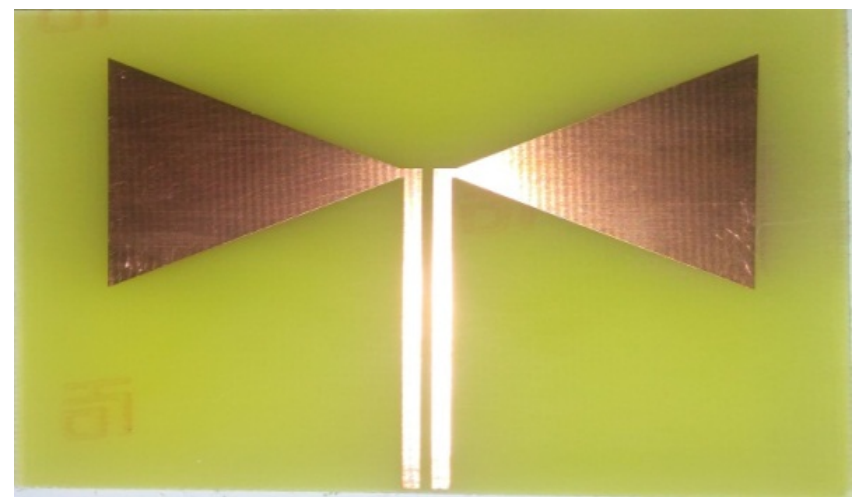

Figure 28. Fabricated conventional bow-tie antenna on FR4 substrate. 


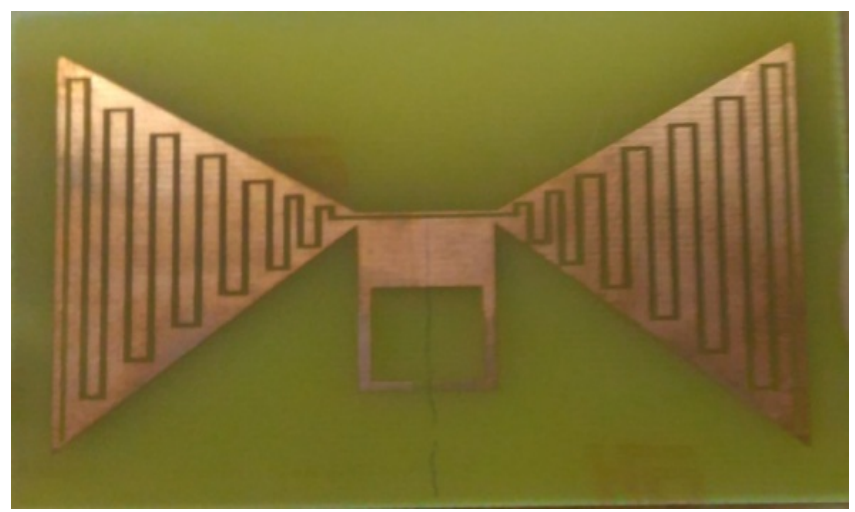

Figure 29. Fabricated modified bow-tie antenna on FR4 substrate.

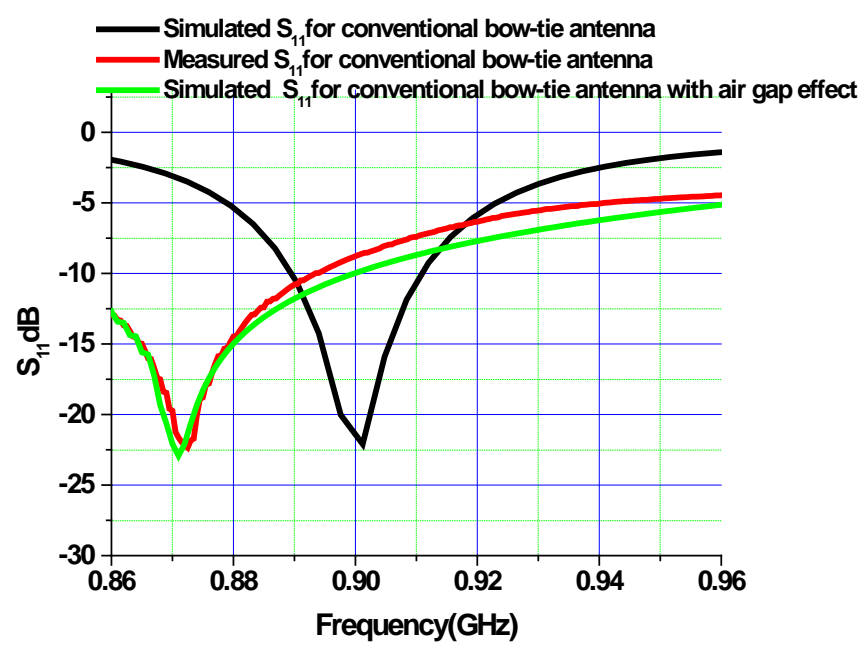

Figure 30. Conventional bow-tie antenna reflection coefficient versus frequency (simulated, measured, simulated with air gap).

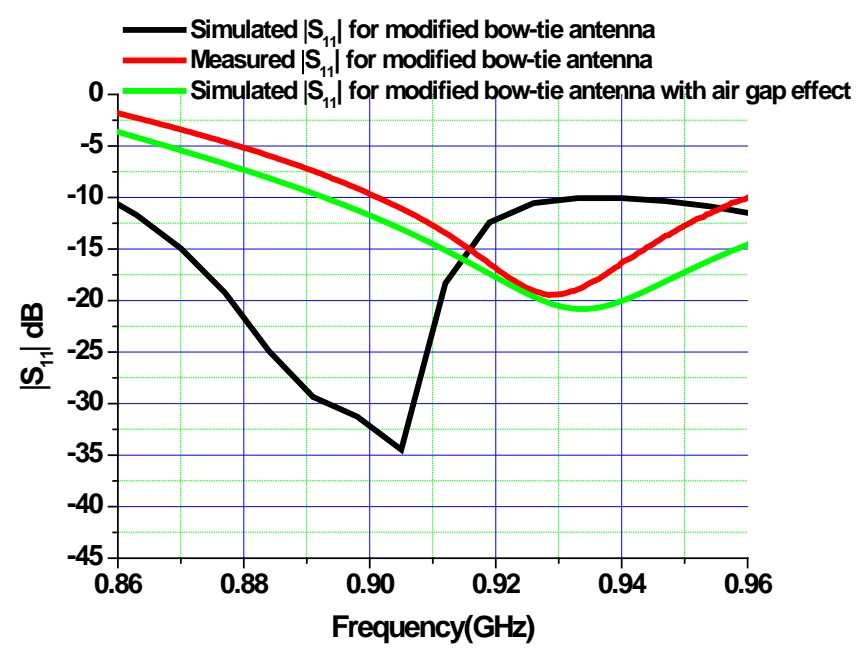

Figure 31. Modified bow-tie antenna reflection coefficient versus frequency (simulated, measured, simulated with air gap).

between ground plane and the half of the antenna structure. So, in the simulation a $1 \mathrm{~mm}$ air gap was inserted between ground plane and the half of the antenna. Now, it can be noticed that the simulated results with air gap 
obtained agrees well with the measured one, Figure 30 and Figure 31.

\section{Conclusion}

A new proposed method for calculating the input impedance of Bow-Tie antenna had been demonstrated. It had been shown that high-accuracy calculation was obtained. Also design curves for input impedance values were developed depending on the geometry of antenna. The proposed design curves were used to design a Bow-Tie type RFID tag antenna. Good matching with the Monza 5 chip reactance is guaranteed for the conventional Bow-Tie antenna but with narrow operating frequency band, which is not suitable for the Europe and North America UHF RFID band range. A modified bow-tie antenna was designed so as to achieve a better conjugate matching to complex chip impedance and also to increase the bandwidth than conventional one. The antenna results demonstrate that it has maximum reading range which extends to $6 \mathrm{~m}$.

\section{References}

[1] Balanis, C.A. (2005) Advanced Engineering Electromagnetics. 3rd Edition, John Wiley \& Sons Inc., Hoboken.

[2] (1989) McGraw-Hill Electrical and Electronics Engineering Series. 5th Edition, Chapter 8, McGraw-Hill, New York, Toronto, London.

[3] Abraham, M. and Becker, R. (1985) Electricity and Magnetism. G. E. Stechert \& Company, New York.

[4] George, J., Deepukumar, M., Aanandan, C.K.., Mohanan, P. and Nair, K.G. (1996) New Compact Microstrip Antenna. Electronics Letters, 32, 508-509. http://dx.doi.org/10.1049/el:19960357

[5] Mahmoud, K.R. (2010) Design Optimization of a Bow-Tie Antenna for 2.45 Ghz RFID Readers Using a Hybrid BSO-NM Algorithm. Progress in Electromagnetics Research, 100, 105-117. http://dx.doi.org/10.2528/PIER09102903

[6] Amin, Y., Chen, Q., Tenhunen, H. and Zheng, L.R. (2012) Performance-Optimized Quadrate Bowtie RFID Antennas for Cost-Effective and Eco-Friendly Industrial Applications. Progress in Electromagnetics Research, 126, 49-64. http://dx.doi.org/10.2528/PIER12020805

[7] Zhang, Z., Zuo, S., Zhang, X. and Fu, G. (2013) Ultra-Wideband Cavity-Backed Bowtie Antenna for Pattern Improvement. Progress in Electromagnetics Research Letters, 37, 37-46. http://dx.doi.org/10.2528/PIERL12110909

[8] Zhao, J.Y., Zhang, Z.Y., Liu, N.W., Fu, G. and Gong, S.X. (2014) Wideband Unidirectional Bowtie Antenna with Pattern Improvement. Progress in Electromagnetics Research Letters, 44, 119-124.

http://dx.doi.org/10.2528/PIERL13122007

[9] Karagianni, E.A. (2015) Electromagnetic Waves under Sea: Bow-Tie Antennas Design for Wi-Fi Underwater Communications. Progress in Electromagnetics Research M, 41, 189-198. http://dx.doi.org/10.2528/PIERM15012106

[10] Khodier, M.M. (1997) Analysis and Design of Broadband Antennas for the Double Quantum Well Terahertz Detector. M.Sc Thesis, Electrical Engineering, Jordan University of Science \& Technology, Jordon, 29-32.

[11] Compton, R.C. (1987) Bow-Tie Antennas on a Dielectric Half-Space: Theory and Experiment. IEEE Transactions on Antennas and Propagation, 35, 622-631. http://dx.doi.org/10.1109/TAP.1987.1144162

[12] Collin, R.E. (1992) Foundations for Microwave Engineering. 2nd Edition, Tata McGraw-Hill, New York.

[13] Pozar, D. (2012) Microwave Engineering. 4th Edition, John Wiley \& Sons Inc., Hoboken.

[14] Sayidmari, K.H. and Fadhel, Y.A. (2013) A Planar Self-Complementary Bow-Tie Antenna for UWB Applications. Progress in Electromagnetics Research C, 35, 253-267. http://dx.doi.org/10.2528/PIERC12103109

[15] Abouelnaga, T.G. (2012) Design and Implementation of Radio Frequency Identification (RFID) Antennas. Ph.D. Thesis, Ain Shams University, Cairo.

[16] Bashri, M.S.R., Ibrahimy, M.I. and Motakabber, S.M.A. (2015) A Compact Wideband Patch Antenna for Ultra High Frequency RFID Tag. Automatika-Journal for Control, Measurement, Electronics, Computing and Communications, 56, 76-83. http://dx.doi.org/10.7305/automatika.2015.04.598

[17] Gao, Y.H., Zhang, Z.H., Lu, H.L. and Wang, H.W. (2012) Calculation of Read Distance in Passive Backscatter RFID Systems and Application. Journal of System and Management Sciences, 2, 40-49.

[18] Impinj Support Portal (2015) Monza 5 Tag Chip Datasheet. https://support.impinj.com/hc/en-us/articles/202756948-Monza-5-Tag-Chip-Datasheet

[19] Zhang, J., Babar, A., Ukkonen, L., Sydanheimo, L., Elsherbeni, A. and Yang, F. (2008) Performance of RFID Bowtie Tag Antenna with Different Impedance Matching. 2008 Asia-Pacific Microwave Conference, Macau, 16-20 December 2008, 1-4. 